NASA Technical Memorandum 104389

$$
\begin{gathered}
\text { N }-04 \\
14447 \\
p .30
\end{gathered}
$$

\title{
Characteristics of a Future Aeronautical Satellite Communications System
}

Philip Y. Sohn

Lewis Research Center

Cleveland, Ohio

Alan Stern

General Electric Company

Princeton, New Jersey

and

Fred Schmidt

Ball Corporation

Bloomfield, Colorado

Prepared for the

Workshop on Advanced Network and Technology Concepts for Mobile, Micro and Personal Communications sponsored by the Jet Propulsion Laboratory

Pasadena, California, May 30-31, 1991

\section{N/Sก}

(NASA-TM-104387) CHARACTERISTICS OF A

FUTURE AERONAUTICAL SATELLITE COMMUNICATIONS

SYSTEM (NASA) $30 \mathrm{p}$

N91-23102

Unclas

G3/04 0014447 


\section{CHARACTERISTICS OF A FUTURE AERONAUTICAL SATELLITE COMMUNICATIONS SYSTEM}

PHILIP Y. SOHN, National Aeronautics and Space Administration, Lewis Research Center, Cleveland, Ohio; ALAN STERN, General Electric Company, Princeton, New Jersey; FRED SCHMIDT, Ball Corporation, Bloomfield, Colorado

\section{ABSTRACT}

A possible operational system scenario for providing satellite communications services to the future aviation community has been analyzed. The system concept relies on a $\mathrm{Ka}$-band $(20 / 30 \mathrm{GHz})$ satellite that ut ilizes Multibeam Antenna (MBA) technology. The aircraft terminal uses an extremely small aperture antenna as a result of using this higher spectrum at Ka-band. The satellite functions as a relay between the aircraft and the ground stations. The ground stations function as interfaces to the existing terrestrial networks such as the Public Service Telephone Network (PSTN). Various system tradeoffs are first examined to ensure optimized system parameters. High level performance specifications and design approaches are generated for the space, ground and aeronautical elements in the system. Both technical and economical issues affecting the feasibility of the studied concept are addressed with the 1995 timeframe in mind.

\section{BACKGROUND}

This concept of providing aeronautical satellite communications at Ka-band was motivated by the seemingly growing need for mobile SATCOM terminals. Recently, several organizations such as AMSC and INMARSAT have announced their plans to provide a full range of mobile - land, sea, and air - communications services using L-band satellite links (Wood and Smith, 1988; Agnew, et al., 1988). For the aviation community, these impending satellite systems promise to offer flexibility and capacity beyond what was previously possible through the longstanding worldwide network of ground stations. The drawback with these systems, however, is the apparent lack of enough spectrum to satisfy the increasing needs of mobile community.

Since Ka-band offers new and uncontested spectrum in excess of billions of hertz, it is deemed appropriate for a future satellite system to utilize this higher part of the electromagnetic spectrum. An added benefit of using Ka-band for mobile terminals, and especially for the aircraft terminals, is the significant reduction in the antenna size. For example, current L-band dish antenna designs call for aperture diameters in the order of $2 \mathrm{ft}$ or larger. A Ka-band dish antenna, however, can be designed at much less than $1 \mathrm{ft}$ in diameter and still provide significantly more performance. Likewise, flush-mountable phased array antennae at $\mathrm{Ka}$-band $\mathrm{can}$ be designed at dimensions significantly smaller than those at L-band. 


\section{BASIC ASSUMPTIONS}

Although a satellite system naturally lends itself to providing global coverage much like that of INMARSAT, this study assumed only one active satellite in orbit above the Atlantic Ocean. The assumption was that the study of one satellite system would suffice at this time and that the results can be applied to a three or more active satellite system with some modifications. The satellite position over the Atlantic Ocean was chosen with the observation that the transoceanic flights between the North America and Europe constitute one of the biggest market share in the airline industry. Geosynchronous altitude was assumed and therefore rules out the coverage of North and South Pole regions. Inclined orbits at lower altitude may bring the benefits of complete Earth coverage and smaller path loss at the cost of requiring more satellites and increased system complexity. Bent-pipe satellite was assumed. A baseband processing satellite would open the possibility for single-hop communication links between the mobile terminals. As it stands, however, the system concept enables satellite links between mobile terminals on one side of the satellite and large hubs, or gateways, on the other side. Only aeronautical terminals were considered in this study, mainly to afford an in-depth look at the feasibility of aircraft antenna system and also to simplify the scope of this effort. However, there is no reason why land or sea terminals would be prevented from becoming a part of this system concept as long as they meet the system specifications.

\section{SYSTEM TRADEOFFS}

The baseline system characteristics were derived by analyzing some of the critical system parameters that affect the technical and economical viability of an operational satellite system.

Service Requirements

The types and quality of services offered by this future system must be comparable and competitive to those of similar systems that are either existing or planned at lower frequency bands. For example, GTE Airfone is an existing system providing in-flight pay phone services to passengers with credit cards. Its service coverage is limited due to its dependence on ground relay stations and its voice quality is primarily dictated by its use of $3 \mathrm{kHz}$ SSB modulation (GTE, 1989; Richards: 1990). On the other hand, INMARSAT and AMSC will soon be offering a full range of satellite communications services to both the cockpit crew and the passengers. They plan to use $9.6 \mathrm{Kbps}$ voice coding but will ultimately move to $4.8 \mathrm{kbps}$. The characteristics of communications services by comparable systems, as well as those for this studied system, are summarized in Table 1 .

\section{Traffic Requirements}

An analytical business model (INMARSAT, 1989) was used to assess the required market size and system capacity. This model quantifies the 
Table 1. Service characteristics

\begin{tabular}{lcc}
\hline Operational system & Voice & Data \\
\hline GTE airfone & $3 \mathrm{kHz}$ SSB & N/A \\
\hline INMARSAT and AMSC & $\begin{array}{c}2.4 \mathrm{kbps}-9.6 \mathrm{kbps} \\
\text { (eventually } 4.8 \mathrm{kbps} \text { ) } \\
\text { at } 1 \mathrm{E}-3\end{array}$ & $\begin{array}{c}\text { Variable rates: } \\
\text { low to high } \\
600 \text { bps }-2.4 \mathrm{kbps} \\
\text { (up to } 10.6 \mathrm{kbps} \text { ) }\end{array}$ \\
\hline Studied scenario & $4.8 \mathrm{kbps}$ at $1 \mathrm{E}-3$ & $\begin{array}{c}\text { Low to high rate } \\
600 \text { bps to } 10.6 \mathrm{kbps}\end{array}$ \\
\hline
\end{tabular}

relationships between the cost of required investment, the required amount of usage-generated revenue, and the service cost per minute to a user when placing a phone call. The model is expressed by the following equation (Palmer, 1990):

$$
\text { CKTCOST }_{S / M I N}=\frac{\$_{S A T}+\$_{\text {GND }}}{3 \cdot\left[525,600 \times U_{N C K T S}\right]}+\frac{\$_{A C}}{3 \cdot\left[525,600 \times U_{A C K C K T S} \times C_{A I R}\right]}
$$

The numerator of the first term, $\$_{S A T}+\$_{G N D}$ is the cost of implementing and maintaining both the space segment and the ground segment. This capital investment is divided by 3 to annualize it over the first 3 years. The resulting amount is further divided by the total number of average circuit-minutes the system is continuously utilized. The result then represents the cost of space and ground segment passed on to the end users on a per circuit-minute basis.

This first part of the equation is plotted in Fig. 1 as a function of capital investment for the space and ground segments and different levels of system usage, $U_{\text {NCKTS }}$. As the usage increases, the classic trend of market expansion lowering the end user cost is evident. For example, if the space and ground segment were $\$ 500 \mathrm{M}$ and equivalent of 500 circuits were continuously used on the average, this figure shows that the service provider would have to charge about $\$ 0.63 / \mathrm{min}$ in order to pay for the space and ground segment within the first 3 years. On the other hand, this cost to the user could be as low as $\$ 0.32$ if the system were utilized twice as much - i.e., equivalent of 1000 channels continuously occupied on the average.

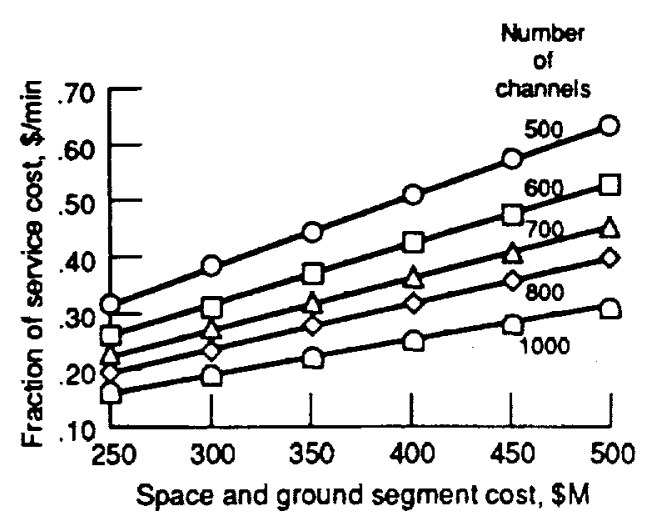

Fig. 1. Service cost.

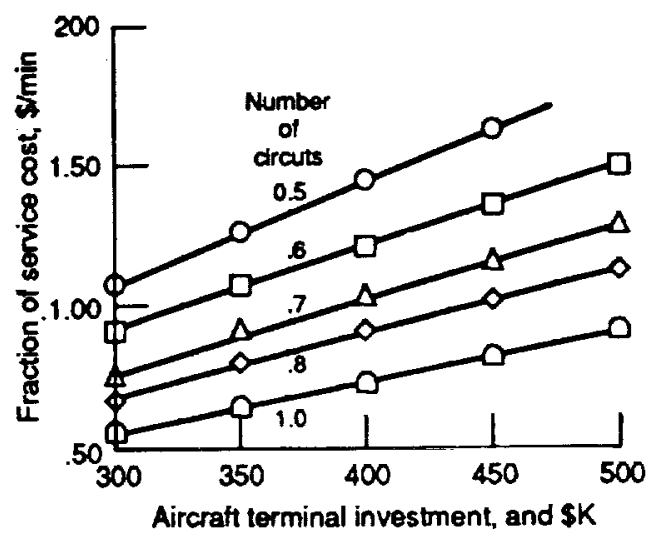

Fig. 2. Service cost. 
The numerator of the second term, $\$_{A C}$, is the capital investment needed for installing and maintaining the aircraft with the needed Ka-band satcom terminal. This is also annualized over the first 3 years and divided by the equivalent number of continuously used circuitminutes. The second term, therefore, calculates the cost of aircraft terminal to be passed on to the end users on a per circuit-minute basis.

This second part of the equation is plotted in Fig. 2 as a function of the capital investment for the aircraft satcom terminal. Again, more users utilizing the terminal translates to lower service cost per each user. If an aircraft satcom terminal were to require capital investment of $\$ 450 \mathrm{~K}$ and used 252 circuit-minutes per day, service cost per circuitminute for using the aircraft terminal would be about $\$ 1.60$. It is conceivable that more usage will be generated and further drive the cost down. The other way for lower service cost, of course, is for the aircraft satcom terminal investment cost to come down.

The equation in total estimates what a service provider would have to charge individual users such that enough revenue can be generated to ensure profit. The space and ground segment with a peak capacity of 8000 full-duplex voice channels is expected to cost about $\$ 450 \mathrm{M}$ to $500 \mathrm{M}$. The aircraft satcom terminal, on the other hand, is expected to cost about $\$ 400 \mathrm{~K}$ to $\$ 500 \mathrm{~K}$. If the average system usage were about 500 to 1000 channels and the average daily usage of aircraft satcom terminal about 252 circuit-minutes, a typical service cost to be charged to the user is estimated at about $\$ 1.92$ to $\$ 2.23 / \mathrm{min}$.

\section{Satellite Coverage Tradeoff}

The geostationary satellite in this conceptual system design is positioned over the Atlantic Ocean. Figure 3 shows the satellite's view of earth from $40 \mathrm{~W}$ longitude. Most of North America, South America, Europe, Africa, and Atlantic Ocean region is within the satellite's field of view. A spot beam satellite partitions this view into many spot areas, and the system tradeoff lies in determining the number, size, and layout of spot beams. Higher gain footprint is preferable since it proportionately reduces the required size of mobile antenna. But higher gain footprint means narrower spot beamwidth, requiring larger number of spots to provide the same extent of satellite coverage.

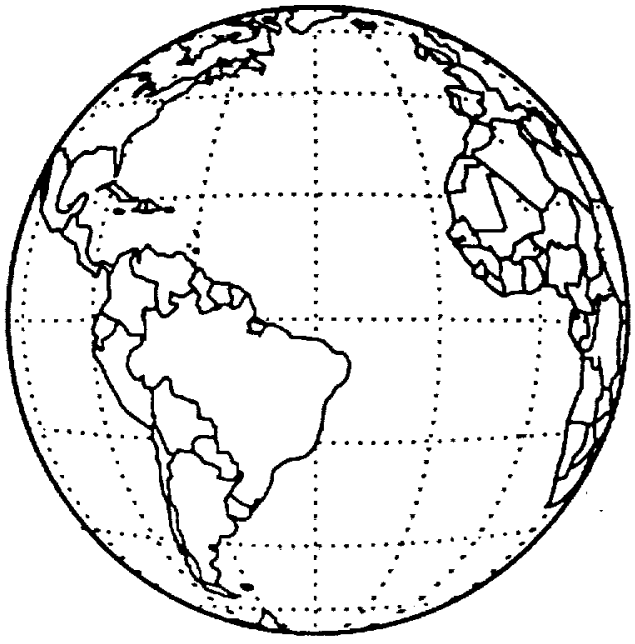

Fig. 3. View from geosynchronous satellite at $40 \mathrm{~W}$.

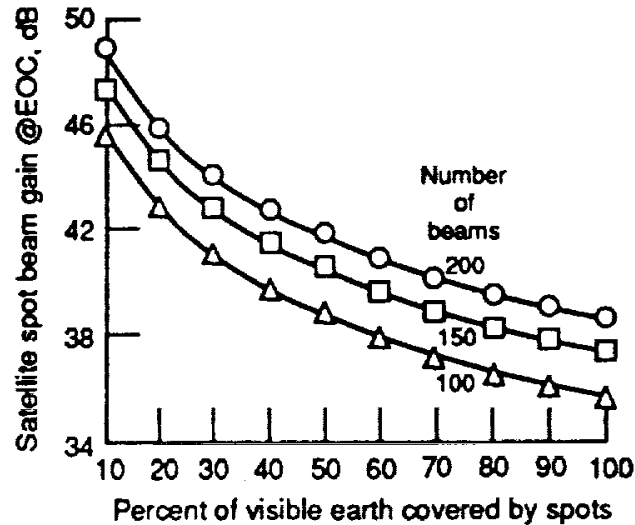

Fig. 4. Number of satellite spot beams. 
Figure 4 illustrates the basic parametric relationship between satellite spot beam gain and fraction of earth illuminated by corresponding number of spot beams. Three curves corresponding to 100,150 , and 200 spots are shown. The equation used to generate this figure is:

$$
S_{E O C}=10 \cdot \operatorname{LOG} 0.5\left[\frac{72.8 \pi}{2 \cdot \cos ^{-1}\left[1-0.014 \cdot\left(\begin{array}{l}
E_{8} \\
N_{B}
\end{array}\right)\right.}\right]^{2} 1-3.0
$$

This equation is derived by assuming the antenna gain and half-power beamwidth (HPBW) characteristics to be approximately equal to those of an aperture with circular symmetry and radially tapered field illumination. The antenna gain efficiency is assumed as 50 percent and the HPBW as 72.8 times the wavelength-to-diameter ratio.

A multibeam Ka-band satellite that produces 100 to 150 beams is considered feasible without further technology developments. The baseline system design for this study assumed a satellite that uses about 140 spot beams to cover the Northern hemisphere of the visible earth with Edge of Coverage (EOC) gain of $40 \mathrm{dBi}$.

The satellite also needs to generate a broader beam(s) to link with the ground stations that are scattered on the continents. This can be done with either one broad beam or several "continental" beams that provide a few more decibels of gain. For simplicity and lack of strong need for reducing the size of fixed ground antennas, one broad beam that covers most of the continents in the Northern hemisphere has been adopted for the baseline system concept.

\section{Link Budget Tradeoff}

The equations used to determine the signal quality relative to white Gaussian noise are given below:

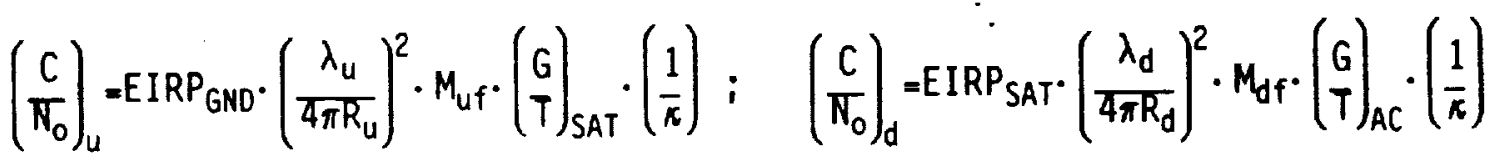

$$
\begin{aligned}
& \left.\left(\begin{array}{c}
c \\
N_{0}
\end{array}\right)=\left[\left(\frac{C}{N_{0}}\right)_{\text {up }}\right]^{-1}+\left[\left(\begin{array}{c}
C \\
N_{0}
\end{array}\right)_{\text {down }}\right]^{-1}\right]^{-1} ; \quad\left(\begin{array}{c}
E_{b} \\
N_{0}
\end{array}\right)=\left(\begin{array}{c}
c \\
N_{0}
\end{array}\right) \cdot\left(\frac{1}{R_{b}}\right)
\end{aligned}
$$

The less obvious but critical factors in the above equations are $M_{u f}$ and $M_{d f}$ - uplink and downlink channel effects. These parameters should account for channel effects such as multipaths, doppler errors, and phase noise. Multipath is likely to be negligible and less of a problem than for land mobile systems. Nevertheless, at low elevation angles, it may cause noticeable degradation to signal quality and therefore necessitate one or a combination of techniques involving narrower antenna beamwidth, more link margin, and spread spectrum modulation. Doppler shift, phase noise, and co-channel interference are other channel effects can cause noticeable degradation to the signal quality if the lirik is not properly designed. Automatic Frequency Compensation 
(AFC) technique can be employed to keep the doppler shift seen by the modem less than 100 to $200 \mathrm{~Hz}$. Likewise, the phase noise induced degradation will be kept to a minimum by using highly stable and precise oscillators in the transmission channel. An additional degradation arising from the use of satellite spot beams, the co-channel interference effects, has been analyzed for spread spectrum multiple access system and has been determined to be less than a few tenths of a decibel (Palmer, 1990).

The ultimate end-to-end service quality given an achieved signal to noise ratio $\left(\mathrm{C} / \mathrm{N}_{0}\right)$ is determined by the modem and codec performances. The primary factors are modulation and baseband channel coding techniques and how they perform in the presence of harmful effects in the channel.

This study did not conduct a detailed analysis of various modulation and coding techniques. Instead, the required signal quality was derived based on the existing and planned system designs. For example, INMARSAT uses Aviation-Binary Phase Shift Keying (A-BPSK) modulation with $1 / 2$ rate coding and baseband interleaving (INMARSAT, 1989). The result is that a BER of $1 E-3$ is achieved for $E_{b} / N_{a}=5.8 \mathrm{~dB}$. On the other hand, the Acts Mobile Terminal (AMT), which is being developed by the Jet Propulsion Laboratory (JPL), will implement Differential Phase Shift Keying (DPSK) modulation with $1 / 2$ rate coding (JPL Acts, 1991). The AMT design expects to achieve $B E R=1 E-3$ at $E_{b} / N_{0}=6.5 \mathrm{~dB}$. As one more reference point, the Hughes Network Systems' study on personal communications using a Ka-band satellite relies on a spread spectrum technique with $1 / 8$ rate baseband coding to achieve the same BER at $E_{b} / N_{0}=5.0 \mathrm{~dB}$. This study adopted as requirements $E_{b} / N_{0}=5.5 \mathrm{~dB}$ and $B E R=1 E-3$ for voice link.

\section{Transponder Capacity}

Given the use of spot beams, it is inevitable that some beams will encounter relatively more traffic than others. For example, the busiest air traffic within the satellite's field of view takes place between the U.S. and Europe (Stamp, 1989). Consequently, the spot beams along this East-West axis will need to be equipped with proportionately larger capacity to handle more traffic.

The satellite transponder's downlink capacity is primarily powerlimited. It is directly dependent on its transmit performance, EIRP, and the receiving terminal's receive performance, G/T. The following equation quantifies the relationship between these two critical parameters:

$$
\text { EIRP }_{S A T}=\frac{\left(\begin{array}{l}
E_{b} \\
N_{o}
\end{array}\right)_{d} \cdot N_{c h} \cdot \kappa \cdot R_{b}}{\left(\frac{\lambda_{d}}{4 \pi R_{d}}\right)^{2} \cdot A L_{d} \cdot\left(\begin{array}{l}
G \\
T
\end{array}\right)_{A C}}
$$

This equation was used to generate Fig. 5 which plots the satellite EIRP $_{E O C}$ performance against aircraft $G / T$ performances for various transponder capacities. It shows that 80 and 40 channel transponder 


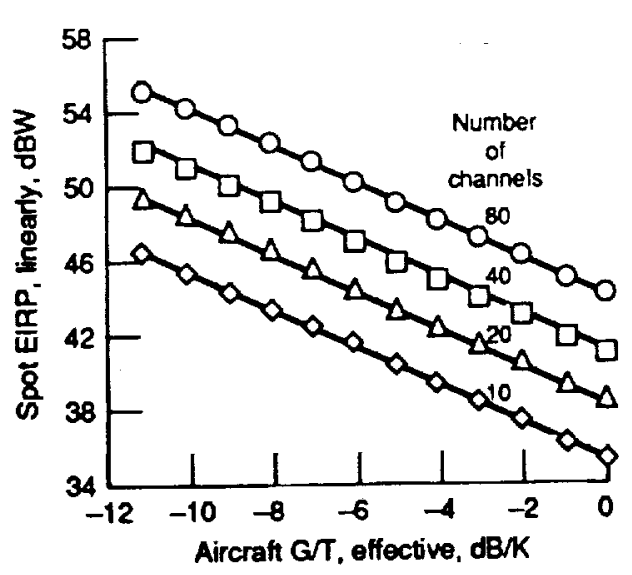

Fig. 5. Downlink spot transponder capacity, 4.8 Kbps voice circuits.

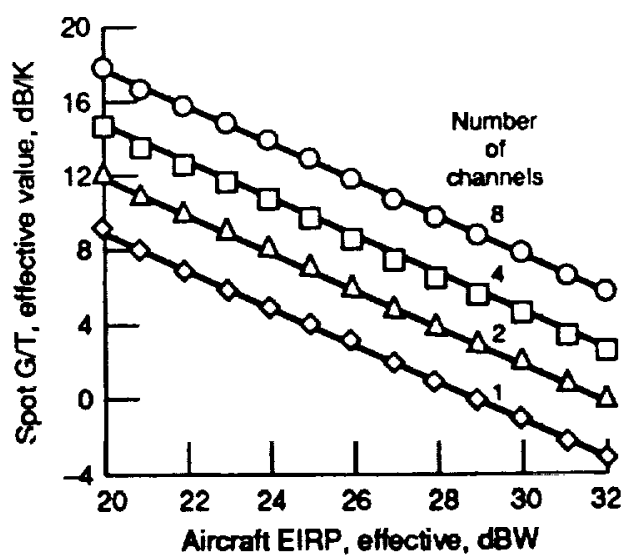

Fig. 6. Aircraft uplink capacity, $4.8 \mathrm{Kbps}$ voice circuits.

capacities, based on aircraft $G / T=-1.8 \mathrm{~dB} / \mathrm{K}$, will require satellite EIRP footprints of $46.2 \mathrm{dBW}$ and $43.2 \mathrm{dBW}$, respectively.

Using FDMA/CDMA type of multiple access in the forward direction

will require linearizing the satellite transmitter in order to prevent severe intermodulation problems. This necessitates backing-off the transmitter's output power level by about 3 to $4 \mathrm{~dB}$. At the same time, voice activation can be used to effectively gain about $3 \mathrm{~dB}$ in satellite power. Consequently, a 40 channel capacity transponder, in conjunction with a satellite beam footprint Edge of Coverage (EOC) gain of $40 \mathrm{dBi}$, will require a Solid State Power Amplifier (SSPA) that can output about $2.1 \mathrm{~W}$, and a higher capacity 80-channel transponder will require a SSPA of about $4.2 \mathrm{~W}$.

In the return uplink direction, the transponder receive capacity is bandwidth-limited while the aircraft transmit capacity is power-limited. The relationship between the satellite receive performance, $(G / T)_{E O C:}$ and the air mobile terminal transmit performance, EIRP $A C$, is quantified by the following equation:

$$
(G / T)_{E O C}=\frac{\left(\begin{array}{l}
E_{b} \\
N_{0}
\end{array}\right)_{U R Q} \cdot N_{A C H} \cdot x \cdot R_{b}}{\left(\frac{\lambda_{u}}{4 \pi R_{u}}\right)^{2} \cdot A L_{u} \cdot E I R P_{A C}}
$$

The above equation is plotted in Fig. 6 which shows the relationship. between satellite receive performance and aircraft transmit performance. It can be seen that an aircraft terminal with EIRP of about $29.5 \mathrm{dBW}$ can uplink eight channels to a satellite spot beam with (G/T) of about $8.3 \mathrm{~dB} / \mathrm{K}$. For a spot beam whose edge of coverage gain is $40 \mathrm{dBi}$, this requires the receive system noise temperature to be less than about $1500 \mathrm{~K}$. Although the feed loss associated with the satellite's multiple fixed beam antenna is expected to be significant, it is not expected to be as high as causing the receive system noise temperature to exceed $1000 \mathrm{~K}$. This is achievable by placing the LNA's very close to the spot beam feeds. 
Table 2. Baseline system characteristics

Spectrum ............... Ka-band, 20/30 GHz

System architecture ... . . Star configuration (Mobile-to-hub) mobile-to-mobile reqs double-hop

Satellite position ...... . 40 W at Geosynchronous altitude Service area . . Northern hemisphere (i.e., 50 percent of Earth visible from the satellite position)

System peak capacity . . . . . 8000 Full-duplex voice circuits

Aircraft peak capacity ..... 8 Full-duplex voice circuits

\section{BASELINE SYSTEM CHARACTERISTICS}

The salient features of the baseline system is summarized in Table 2. It relies on a star network architecture where the Aircraft Satcom Terminals (AST) communicate with Gateway stations via the Ka-band satellite. The Gateways interface with the existing terrestrial networks such as the Public Service Telephone Network (PSTN) and thereby provide the last connection to the destination on the ground.

In the "return" (or "in-bound") direction, the AST transmission is uplinked to the satellite, downlinked to a Gateway station, and fed into the terrestrial network for reception by the ground user. In the "forward" (or "out-bound") direction, the ground user transmission is received by a Gateway station, uplinked to the satellite, and downlinked to the user on board the aircraft. Aircraft-to-aircraft communication will require going through the satellite twice - i.e., double-hop - and is not expected to be in much demand.

In the forward direction, ground stations uplink at $30 \mathrm{GHz}$ to the satellite using Frequency Division Multiple Access (FOMA). There are 140 distinct frequency bands in this forward uplink direction - one per forward downlink spot beam - and the Gateways must place carriers in the frequency bands dictated by the position of their intended aircraft. These hub transmissions are received by the satellite's broad beam and then frequency trans?ated into the appropriate spot beams. The spot beams downlink at $20 \mathrm{GHz}$ and utilize seven distinct frequency bands. Seven contiguous spot beams - i.e.. a cluster of seven beams - are assigned these seven downlink bands and the clusters are repeated 20 times for 140 beams. This arrangement produces frequency reuse factor of 20 for the spot beam side of the system. Higher frequency reuse can be achieved by opting for a smaller cluster size. For example, a cluster size of 4 will yield a frequency reuse factor of 35 . The advantages of this smaller cluster size are more efficient use of spectrum and simpler synthesizer for the aircraft terminal. The disadvantages are larger number of satellite local oscillator frequencies and higher interbeam interferences.

In the return direction, the aircraft terminals uplink in one of seven frequency bands centered at about $30 \mathrm{GHz}$. The satellite then performs similar frequency translation in a reverse sense such that receptions from the $14030-\mathrm{GHz}$ spot beams are mapped to $14020-\mathrm{GHz}$ frequency bands for downlink through the broad beam. If FDMA/SCPC access scheme were to be used with $25 \mathrm{kHz}$ spacing between voice channels, an 80 channel spot would require a frequency band of $2.0 \mathrm{MHz}$ (employing spread spectrum access would require wider band). The 
resulting spectrum need for the system then would be about $225 \mathrm{MHz}$ at $20 \mathrm{GHz}$ and another $225 \mathrm{MHz}$ at $30 \mathrm{GHz}$.

Due to the use of fixed spot beams, handoff operations will be needed to provide continuous satellite links. This will involve both the aircraft and ground transceivers switching to a new frequency band since adjacent spot beams utilize different frequency bands. Since the spot beams are designed for $G_{E Q C}$ of $40 \mathrm{dBi}$ (which translates to HPBW of about $1.1^{\circ}$ and footprint diameter of $736 \mathrm{~km}$ ) and typical aircraft velocities range from 800 to $960 \mathrm{Kmph}$, handoff procedure will take place at least once every 50 to $55 \mathrm{~min}$. This is conceptually similar to the handoff operation done in the existing terrestrial cellular systems. But the aeronautical satellite system has the possibility of using the aircraft's navigational information to its advantage. This should prove to be an advantage compared to the terrestrial cellular system which presently has no way of knowing exactly where the mobile vehicle is, which direction it is headed, how fast it is moving, etc. Unlike the existing cellular vehicles, the aircraft mobile system has the option to actually rely on predictable and accurate flight data for handoff operation.

The use of narrower (compared to those of INMARSAT) spot beams also imply a need for more stringent specification on power control algorithm. The failure to implement good power control for transmitting mobile terminals would render FDMA type of multiple access system inefficient and low quality. In the L-band systems where the satellite beams are much broader, the change in satellite G/T experienced by moving aircraft is rather gradual. For narrower spot beams at Ka-band, however, satellite G/T performance changes more quickly with aircraft position. Consequently, power control algorithm will be exercised more frequentiy in this $\mathrm{Ka}$-band spot beam satellite system. Power control in steps of $1 \mathrm{~dB}$ is expected to be sufficient.

Because the Ka-band aeronautical satellite link is expected to experience significant doppler shift effects, doppler compensation technique will play a major role in the system operation. The contribution from the aircraft velocity can be quite large. The equation below shows the doppler error to be expected as a function of the carrier frequency and the relative geometry between the aircraft and the satellite. It does not account for the doppler error that gets induced by the orbital drift of a geosynchronous satellite.

$$
f_{D}=f_{T} \cdot \frac{V_{A C}(m / s) \cdot \cos (\theta)}{3 \times 10^{8}(\mathrm{~m} / \mathrm{s})}
$$

For aircraft velocity of $900 \mathrm{Kmph}$, the maximum doppler can be as large as $25 \mathrm{kHz}$ at $30 \mathrm{GHz}$, and $16.7 \mathrm{kHz}$ at $20 \mathrm{GHz}$. Although these extreme cases arise mostly for aircraft that operate at very low elevation angle, doppler effects are nevertheless significant throughout the system. Since this doppler error is caused by aircraft motion, it should be detected and compensated immediately at the individual aircraft. This can be accomplished by relying on a pilot channel and/or aircraft navigational data. 


\section{Baseline Satellite Characteristics}

The baseline Ka-band satellite has a peak capacity of about 8000 full-duplex voice circuits. It is positioned over the Atlantic Ocean at geosynchronous altitude. It operates in a bent-pipe mode, transparent to the modulation used by the terminals. It produces a broad beam and about 140 narrow spot beams to cover the Northern hemisphere in the Atlantic region. The spot beams will be used by the mobile terminals and enable significant reduction for the AST antenna size relative to the ones used at L-bund. Some of the spot beams (about 70) that are pointed at high air traffic density regions will be equipped with more transmit power and correspondingly more bandwidth to handle more traffic ( 80 voice channels per beam). The remaining spot beam will be equipped to handle about 40 voice channels per beam.

The performance characteristics of the satellite is summarized in Table 3 . The satellite provides spot beam coverage of the Northern hemisphere as shown in Fig. 3. A block diagram of the satellite's communications subsystem is given in Fig. 7. It essentially consists of two parts. The top portion contains the forward transponders going from the broad beam to 140 spot beams, while the bottom half contains the return transponders that carry communications traffic in the opposite directions. Table 4 lists the equipments necessary to implement this block diagram. Spacecraft on-orbit weight and steady-state power requirements are tabulated in Tables 5 and 6.

The estimated cost for the space segment includes two satellites in orbit, one active and the other a backup. The first satellite is estimated at \$150M, the second one at \$75M. Allowing \$150M for launch and operation of the two satellites, the total cost of the space segment is estimated at $\$ 375 \mathrm{M}$.

\section{Baseline Ground Stations}

The ground segment includes a master control station (MCS) and several (about 5 to 10) Gateway stations. Their salient performance parameters are listed in Table 7. The MCS will simultaneously serve as a Gateway, ., and one of the Gateways will be equipped to act as a backup MCS.

Table 3. Satellite performance characteristics

\begin{tabular}{|c|c|c|}
\hline Peak capacity & \multicolumn{2}{|c|}{$\begin{array}{l}8000 \text { Full-duplex voice } \\
\text { circuits }\end{array}$} \\
\hline Spot beams & $\begin{array}{c}\text { NUMBER OF } \\
\text { HPBW } \\
\text { EIRP } \\
(G / T)_{\text {EOC }} \\
\end{array}$ & $\begin{array}{c}140 \\
1.1^{\circ} \\
43.2 / 46.2 \mathrm{dBW} \\
-8.3 \mathrm{~dB} / \mathrm{K} \\
\end{array}$ \\
\hline Broad beam & $\begin{array}{l}\text { EIRP }_{E O C} \\
(G / T)_{E O C}\end{array}$ & $\begin{array}{r}35.5 \mathrm{dBW} \\
-3.5 \mathrm{~dB} / \mathrm{K} \\
\end{array}$ \\
\hline
\end{tabular}


Table 4. Satellite communications payload equipment list

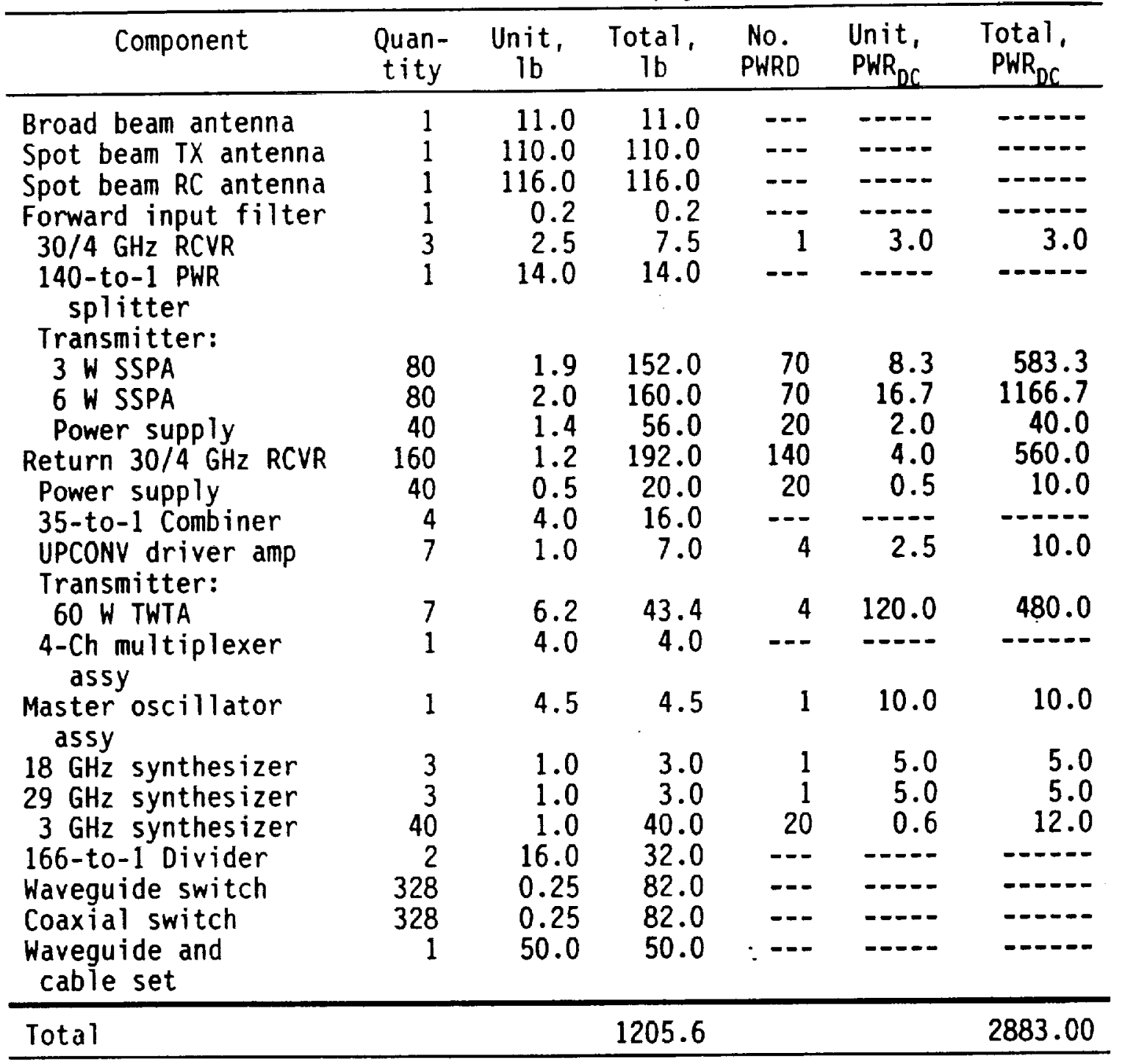

Table 5. Satellite or orbit weight

\begin{tabular}{lr}
\hline \multicolumn{1}{c}{ Subsystems } & Weight, lb \\
\hline Communications payload & 1205 \\
TT\&C & 120 \\
Attitude control & 154 \\
Propulsion & 304 \\
Power & 700 \\
Thermal & 110 \\
Structure & 455 \\
Harness & 300 \\
Mechanical assemblies & 61 \\
Balance weights & 30 \\
Margin, 10 percent & 346 \\
\hline Total & 3775 \\
\hline
\end{tabular}


Table 6. Steady state power requirement

\begin{tabular}{lr}
\hline \multicolumn{1}{c}{ Subsystem } & Power $_{\text {dc }}$, W \\
\hline Communications payload & 2883 \\
Thermal & 224 \\
Attitude control & 116 \\
TT\&C & 80 \\
Power subsystem & 20 \\
Harness power loss & 22 \\
\hline Total & 3347 \\
\hline Battery charge at equinox & 415 \\
\hline Total solar array capacity & 3762 \\
\hline
\end{tabular}

Table 7. Ground station performance parameters

\begin{tabular}{lc}
\hline Peak capacity & $\begin{array}{c}1000 \text { to } 2000, \\
\text { full-duplex voice chs }\end{array}$ \\
\hline Dish diameter & $7.3 \mathrm{M}$ \\
Angenna gain & $61.1 \mathrm{dBi}$ at $20 \mathrm{GHz}$ \\
& $64.6 \mathrm{dBi}$ at $30 \mathrm{GHz}$ \\
G/T & $31.6 \mathrm{~dB} / \mathrm{K}$ \\
EIRP & $76.7 \mathrm{dBW}$ \\
\hline
\end{tabular}

The MCS serves the important function of supervising and synchronizing the system A functional block diagram of the MCS is given in Fig. 8 (Palmer, 1990). The supervision role involves observing signaling channels and making channel assignments. There are 140 access channels (one for every spot beam) that are used by ATS's for making channel requests. When a request is received, a call processing computer performs channel assignment. This involves instructing the AST to use a specific frequency slot and notifying the selected Gateway station to tune to the corresponding RF channel with the ground user on the other end of the line. Another kind of channel assignment also takes place under the supervision of the MCS as the aircraft flies through a beam and enters the next spot beam. This interbeam handover process also involves responding to the ATS request and assigning new RF channels both to the aircraft and the Gateway but without interrupting the on-going communications line. The MCS is also responsible for synchronizing the system time and frequency references. This can be accomplished through a master control channel which will be received by all terminals in the system.

The Gateways act as interfaces between the satellite system accessed by the mobile users and the terrestrial network which connects to the ground users. The functional block diagram of a Gateway is essentially same as that of the MCS, except for the MCS-specific equipments that will be missing. One of its key equipments is the interface to the terrestrial network which can be implemented by a T-carrier 


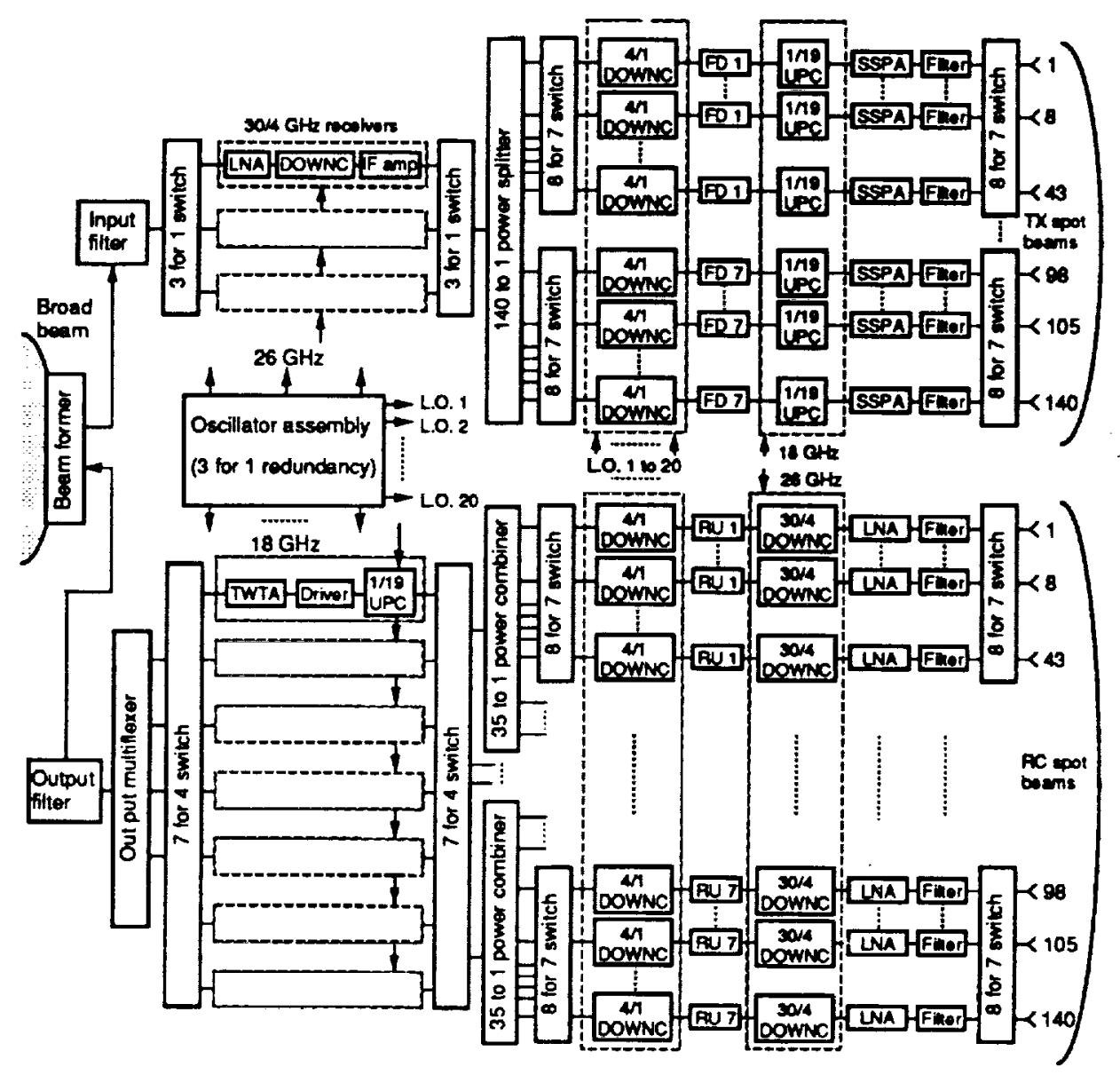

Fig. 7. Satellite communications subsystem. 


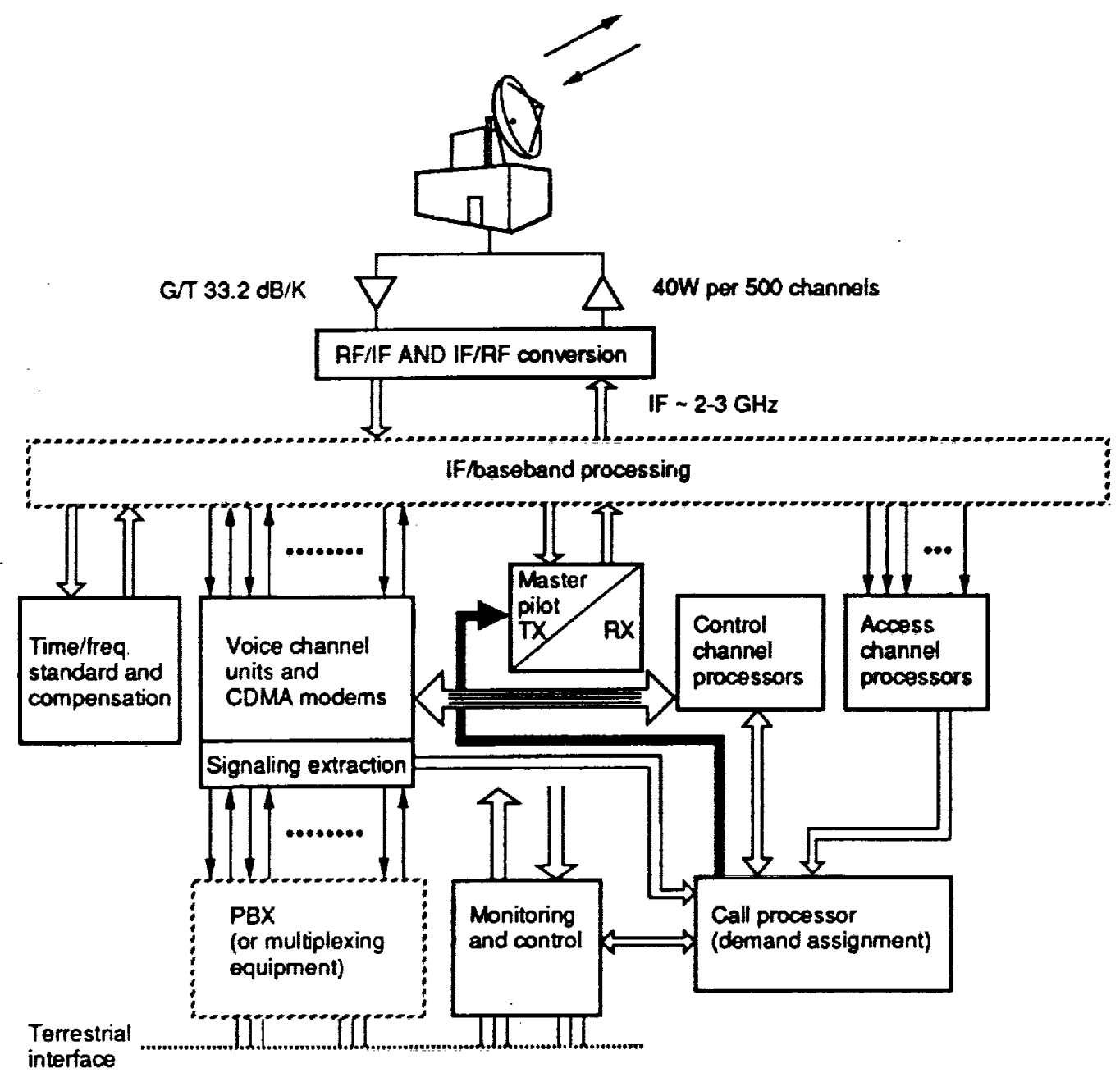

Fig. 8. Block diagram of master station.

multiplexing switch. It will utilize a channel control processor to listen and respond to the master control channel.

The ground segment, including one MCS and nine Gateway stations (one of which is equipped to serve as a backup MCS) has been estimated to cost about $\$ 100 M($ Palmer, 1990).

\section{Baseline Aircraft Satcom Terminal}

The baseline performance characteristics of aircraft satcom terminal are summarized in Table 8 . Its block diagram is shown in Fig. 9 for the case of using a dish antenna atop the fuselage. Significant differences between this and the near-future INMARSAT Aircraft Earth Stations (AES) include higher communications capacity, smaller antenna size, wider range for Automatic Frequency Compensation (AFC) circuit, and synthesize for tuning to any one of seven frequency bands at 20 to $30 \mathrm{GHz}$. The additional details required for interfacing the aviation satcom terminal with other aircraft equipments such as Aircraft Communications Addressing and Reporting System (ACARS) and Multi-purpose Control and Display Units (MCOU) have not been investigated as a part of this study. The impending INMARSAT aviation terminals will adhere to 
Table 8. Baseline aircraft SATCOM terminal performance

\begin{tabular}{|c|c|c|}
\hline Peak capacity & \multicolumn{2}{|c|}{$\begin{array}{l}4 \text { voice }(4.8 \mathrm{kbps}) \mathrm{chs} \text { and } \\
2 \text { data }(2.4 \text { to } 9.6 \mathrm{kbps}) \text { chs }\end{array}$} \\
\hline $\begin{array}{l}\text { TX/RC center } \\
\quad \text { frequencies } \\
\text { Bandwidth } \\
\text { EIRP } \\
\text { G/T } \\
\text { Polarization } \\
\text { Tracking } \\
\quad \text { requirements } \\
\end{array}$ & \multicolumn{2}{|c|}{$\begin{array}{c}30 / 20 \mathrm{GHz} \\
>200 \mathrm{MHz} \\
32.5 \mathrm{dBW} \\
-1.8 \mathrm{~dB} / \mathrm{K} \\
\text { Circular } \\
\text { Geostationary satellite } \\
\text { (greater than } 5^{\circ} \text { in elevation) }\end{array}$} \\
\hline \multirow[t]{2}{*}{$\begin{array}{l}\text { Antenna } \\
\text { alternatives }\end{array}$} & Nonconformal & $\begin{array}{l}\text { Low profile radomed dish } \\
\text { Atop the fuselage } \\
\text { No blind spots } \\
\text { Cheaper } \\
\text { Near-term alternative }\end{array}$ \\
\hline & Conformal & $\begin{array}{l}\text { Flush-mount } \\
\text { One on each side of fuselage } \\
\text { Blind spots exist } \\
\text { More expensive } \\
\text { Long-term alternative }\end{array}$ \\
\hline
\end{tabular}

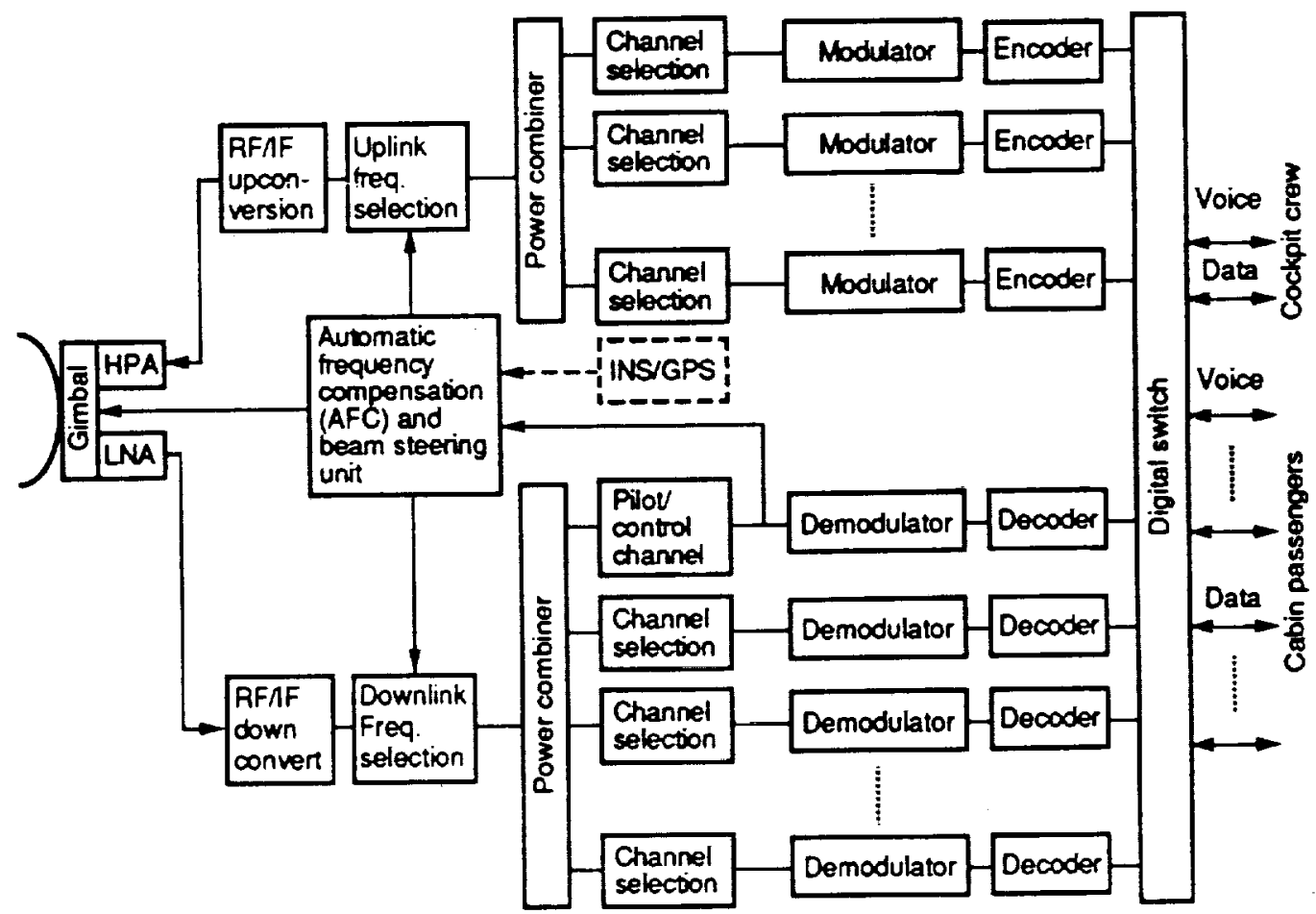

Fig. 9. Aircrah SATCOM terminal, with dish antenna. 
the guidelines set forth in ARINC Characteristic 741. A similar document, or a modification to the Characteristic 741 , will be needed to guide the development and installation of future Ka-band aviation terminals.

Aircraft Antenna Alternatives. The Ka-band antenna for aircraft terminal was identified as a potential feasibility risk from the inception of the study. Its transmit and receive beams must be high gain and agile to dynamically steer in the direction of the satellite without incurring unacceptable pointing losses and interferences to other satellites. It should be installed without compromising the integrity of the aircraft structure and the efficiency of the aircraft aerodynamic shape. It must be able to withstand hostile environmental conditions such as lightening, static discharge, and electromagnetic pulse hazards. And most importantly, it must be cost effective for market viability.

In order to address these antenna related issues in detail, two independent antenna studies were conducted. The main objectives were twofold: (1) to examine all potentially viable antenna approaches; and (2) to propose two designs that are most feasible both technically and economically. As a result, two alternative approaches are identified. The first approach involves installing a mechanically scanning dish antenna atop the fuselage. This involves very little technology risk and could be implemented in the near future. Although it presents a small protrusion, it is very low profile and covered with a radome shaped to virtually eliminate any noticeable air drag. The second approach involves flush-mounting numerous phase arrays at various strategic points in the aircraft. This has the advantage of being conformal to the aircraft and probably most desired by the airline industry. It will, however, involve longer development time and higher capital investment before becoming cost-competitive with the dish antenna.

Dish Antenna Design (Jong, 1990). The prime candidate dish antenna that meets all performance specifications is illustrated in Fig. 10 . It uses a cassegrain configuration which consists of a main reflector (5.8 in.) and a shaped subreflector ( 1.6 in.) at a focal length of $1.87 \mathrm{in.}$. It is based on well developed technology and employs existing or modified hardware. The critical component is the dual-band coaxial wave guide feed with a ring choke. Its design already exists at $20 / 44 \mathrm{GHz}$, and it can be modified to $20 / 30 \mathrm{GHz}$ band. The two-axis gimbal is a scaled down INMARSAT gimbal currently available from E-Systems. There is enough real estate behind the main reflector for housing power amplifier (PA) and low noise amplifier (LNA). This design is low risk and possesses the potential for performance upgrade without significant cost impact.

The performance of this dish antenna can be predicted by using Tables 9 and 10 and Figs. 11 and 12 . The two figures show receive and transmit antenna performances for the ideal case (i.e., 100 percent antenna efficiency and no loss between the antenna and the active devices) and the two tables contain estimated loss budgets for the proposed design. The size of the dish diameter is primarily driven by the required $G / T$. This is because the $G / T$ performance is hard to 


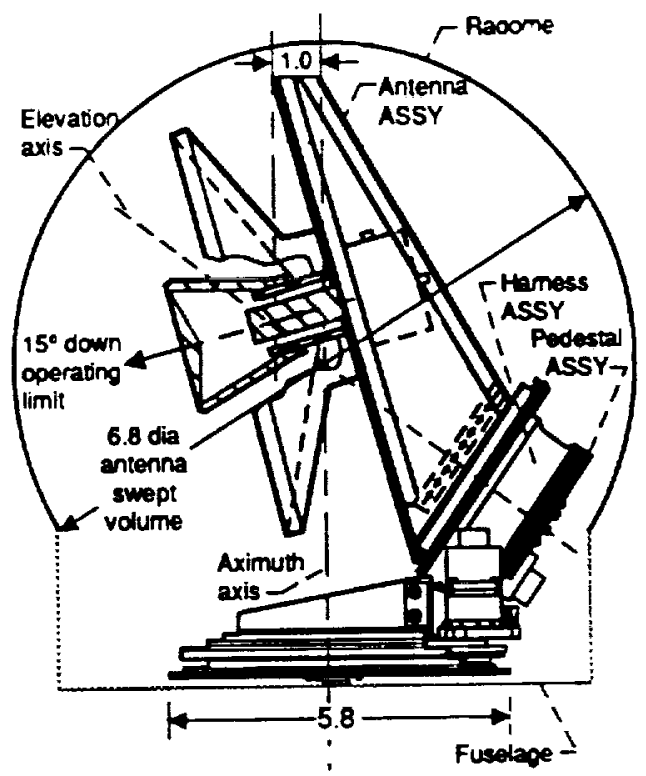

Fig. 10. Layout of reflector antenna and gimbal assemblies.

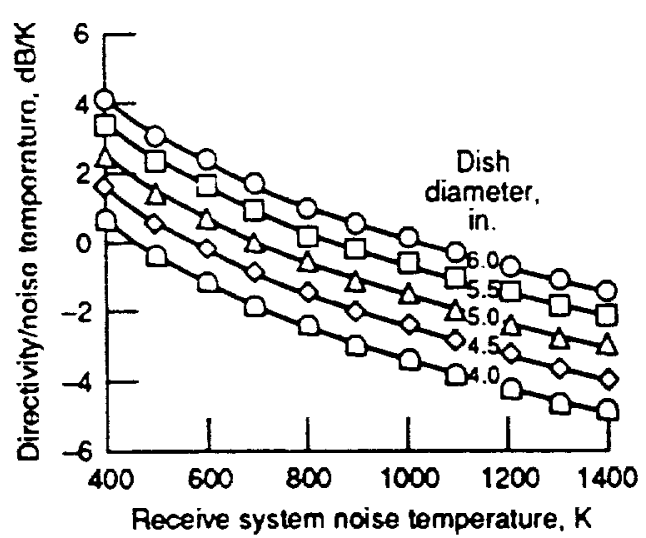

Fig. 11. Aircraft dish antenna receive pertormance.

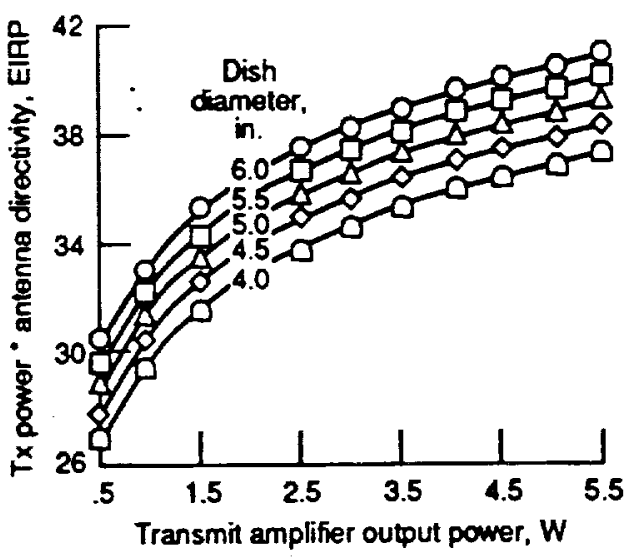

Fig. 12. Arrcraft dish antenna transmit pertomance. 
Table 9. Dish $20 \mathrm{GHz}$ receive chain loss and noise temperature computation

\begin{tabular}{|c|c|c|c|c|}
\hline & $\begin{array}{c}\text { Loss: non- } \\
\text { dissipative, } \\
\mathrm{dB}\end{array}$ & $\begin{array}{c}\text { Loss: } \\
\text { Dissipative, } \\
\mathrm{dB}\end{array}$ & $\begin{array}{c}\text { Individual } \\
\text { temperature, } \\
K\end{array}$ & $\begin{array}{c}\text { System } \\
\text { temper- } \\
\text { ature, } \\
K\end{array}$ \\
\hline $\begin{array}{l}\text { Sky } \\
\text { Radome } \\
\text { Pointing error } \\
\text { Subref blockage } \\
\text { Surf tolerances } \\
\text { Amplitude taper } \\
\text { Spillover } \\
\text { Feed } \\
\text { Filter }\end{array}$ & $\begin{array}{l}--. \\
0.2 \\
0.2 \\
1.6 \\
0.2 \\
0.5 \\
1.0 \\
0.2 \\
---\end{array}$ & \begin{tabular}{l}
$0 .-$ \\
0.8 \\
.--- \\
--- \\
.-- \\
\hdashline.- \\
0.8 \\
1.0
\end{tabular} & \begin{tabular}{l}
15.0 \\
58.7 \\
\hdashline..- \\
\hdashline..- \\
\hdashline..- \\
58.7 \\
75.1 \\
\end{tabular} & 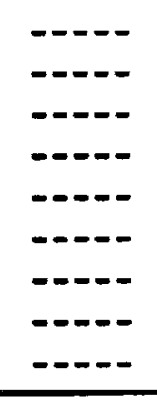 \\
\hline Total & 3.9 & 2.6 & --- & 428.9 \\
\hline LNA, $3 \mathrm{~dB} N \mathrm{NF}$ & $-\ldots$ & --- & 290.0 & ----- \\
\hline
\end{tabular}

Table 10. Dish EIRP loss

\begin{tabular}{lc}
\multicolumn{2}{c}{ computation } \\
\hline & Loss, dB \\
\hline Feed & 1.0 \\
Spillover & 1.0 \\
Amplitude taper & 0.5 \\
Surf tolerance & 0.4 \\
Subref blockage & 1.6 \\
Point ing error & 0.2 \\
Radome & 1.2 \\
\hline Total tx loss & 5.90 \\
\hline
\end{tabular}

improve without increasing the dish diameter. The transmit performance, on the other hand, can be improved to a certain extent by increasing power amplifier wattage.

Dish antenna installation (Schmidt, 1990). There are several factors which must be considered when determining the optimum antenna mounting location. The most important factor is aircraft blockage. It is important to find a location where the aircraft structure will not block significant areas of its coverage region. From this standpoint of minimum blockage, the optimum mounting locations for any airborne SATCOM antenna are on the top surface of the fuselage and the top of the tail. other factors to be considered are drag, the availability of space inside of the aircraft to mount support boxes, and the accessibility of such places for installation and maintenance. The fuselage position is the clear winner for all of these considerations except for drag. The tail mount location offers the potential advantage of reduced impact on 


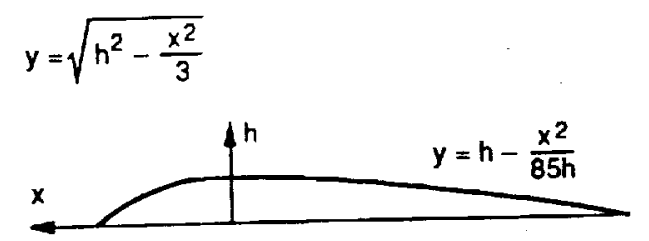

- Radome length $=12.2 \times$ height

- Walls assumed to be 0.1 in. to 0.2 in. fiberglass

Fig. 13. Radome design. (For dish antenna.)

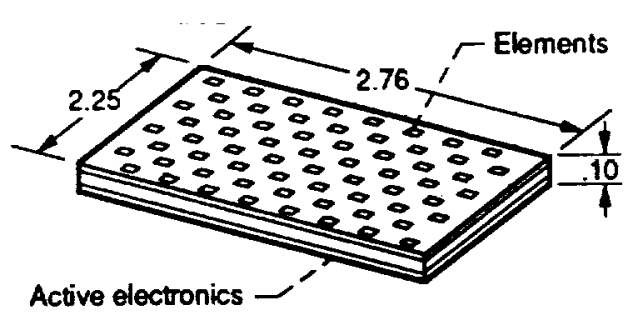

Fig. 14. Phased array concept.

aircraft drag; however, its harsh vibration and thermal environment combined with limited real estate could spell problem for the positioner and the HPA.

Radome. Given the antenna installation on top of the fuselage, a radome must be used both to protect the antenna from the environment and to minimize aerodynamic drag. The teardrop radome shape is illustrated in Fig. 13 along with the equations which are used to generate the teardrop shape. The length of the radome is 12.2 times its height. This large length-to-height ratio is required to keep air moving smoothly over the radome. Using this formulation, the radome length and height for the recommended dish antenna is about 85 in. and 7 in., respectively. The small diameter of the dish keeps the required radome height very minimal, much. less than $1 \mathrm{ft}$. While this is not conformal, it is generally surmised that the protrusion is so small and below the critical threshold that any disturbance to the aerodynamics would be virtually unnoticeable.

Conformal phase array design (Schmidt, 1990). From the standpoint of minimizing aeronautical drag and installation costs, the most desirable approach is to use a set of flush-mounted electronically steerable phased arrays that can be integrated into the aircraft skin. The receive array concept (which, except for dimensions, is identical to the transmit array) is illustrated in Fig. 14. It consists of a front-side "element board" that contains all the radiating elements and a back-side "RF electronics board" which contains the power divider, phase shifters, and LNA's. This design is quite similar to the approach used in many conventional phased-arrays, except for the fact that it uses one single RF board in place of several boards mounted perpendicular to the element board. Ball has used this type of packaging scheme in the MSAT, Advanced Active Phased Array (AAPA), and Mobile Communications Terminal (MCT) antenna designs.

Figure 15 illustrates the transmit array package. The RF electronics board has an RF connector and a dc connector which go through holes in the aircraft skin for coupling with the equipment inside of the aircraft. One transmit and one receive array are mounted on each side of the aircraft. The receive array package looks identical except for dimensions. The antennas are packaged separately in order to alleviate packaging complexity and to aid in isolating the receiver from the transmit energy.

The functional block diagram of transmit and receive arrays are shown in Figs. 16 and 17 . Distributed amplifiers and phase shifters are used - i.e., one phase shifter and one HPA or LNA assigned to each 


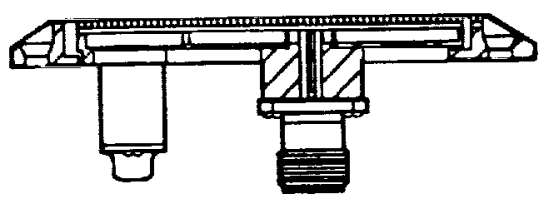

Cross section.
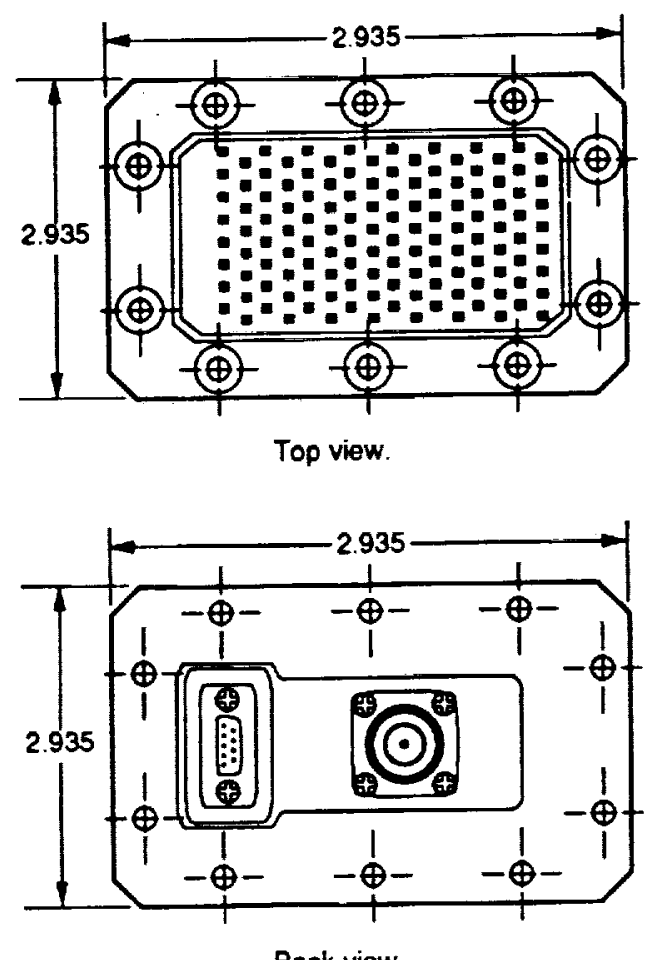

Back view.

Fig. 15. Illustration of transmit phase array package.

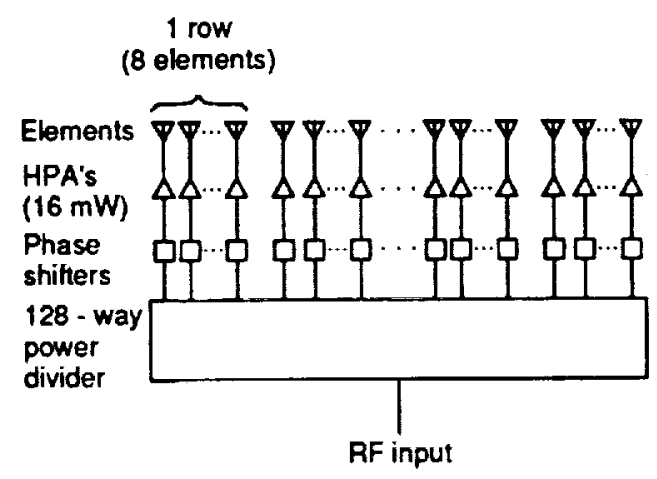

Fig. 16. Transmit array block diagram.

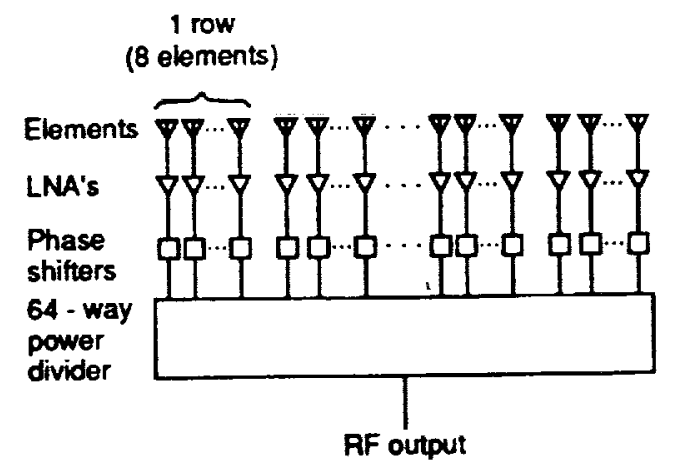

Fig. 17. Recoive array block diagram.

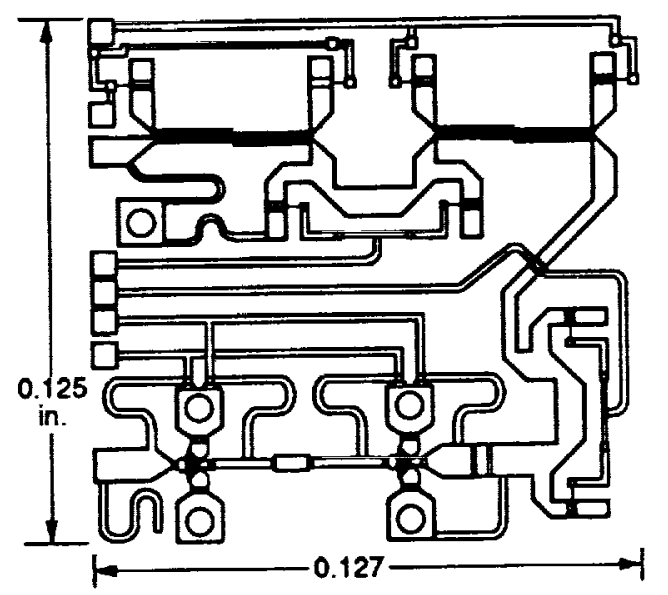

Fig. 18. Transmit phase shifter/HPA

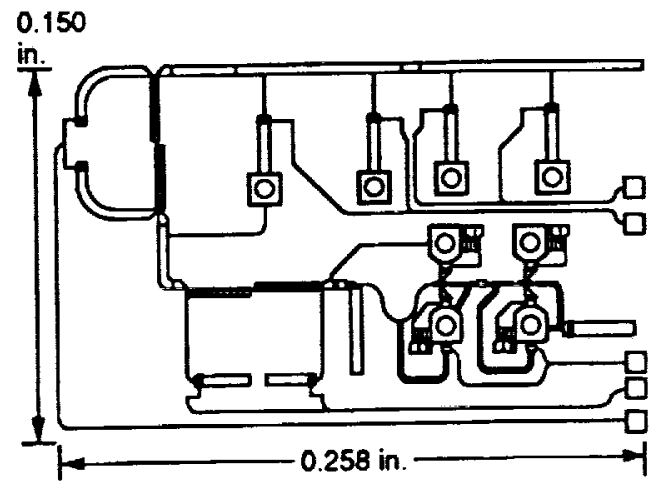

Fig. 19. Receive phase shifter/LNA. 
transmit or receive element. This arrangement of distributed amplification is beneficial since the losses introduced by the power divider and phase shifters do not degrade the array's transmit or receive performance. Individual phase shifters are specified because the array must scan from boresight to $60^{\circ}$ without introducing grating lobes; schemes which feed several elements from a single phase shifter will not be able to suppress grating lobes for the required scan angles.

The phase shifters and amplifiers are implemented using MIC technology in order to fit all the required electronics for each element into the area behind the element. For the transmit array, a single HPA and phase shifter are mounted on a single chip and placed just beneath each transmitting element in the array. Similarly, for the receive array, a LNA and a phase shifter are mounted on a single chip and placed behind every receiving element. The transmit chip design, presented in Fig. 18, is a scaled up version of the $44 \mathrm{GHz}$ MIC chip designed as a part of Ball's MILSTAR array work. The majority of the components are frequency sensitive, and the dimensions primarily scale in proportion to the wavelength. The chip contains a four-bit phase shifter and a twostage HPA; FET's are ușed both in the phase shifter and the HPA. The receive MMIC chip, which is derived from the $20 \mathrm{GHz}$ MILSTAR design, is shown in Fig. 19.

Table 11. Transmit phased array EIRP prediction

\begin{tabular}{|c|c|c|c|}
\hline & 8 by 16 array & 12 by 16 array & 16 by 16 array \\
\hline $\begin{array}{l}\text { Directvty } \\
\text { PIN, dB } \\
\text { Feed-thru, dB } \\
\text { Fed-thw } \\
\text { Element, dB } \\
\text { Polarization, dB } \\
\text { Radome, dB } \\
\text { Pointing, dB }\end{array}$ & $\begin{array}{r}22.81 \\
3.00 \\
-0.45 \\
-0.62 \\
-0.20 \\
-0.50 \\
-0.20\end{array}$ & $\begin{array}{r}24.31 \\
4.50 \\
-0.45 \\
-0.62 \\
-0.20 \\
-0.50 \\
-0.20 \\
\end{array}$ & $\begin{array}{r}25.81 \\
6.00 \\
-0.45 \\
-0.62 \\
-0.20 \\
-0.50 \\
-0.20 \\
\end{array}$ \\
\hline EIRP $_{\text {PRED }}, \mathrm{dBW}$ & 23.84 & 26.84 & 29.84 \\
\hline
\end{tabular}

Table 12. Receive phased array G/T performance prediction

\begin{tabular}{|c|c|c|c|c|c|c|}
\hline & \multicolumn{2}{|c|}{8 by 8 array } & \multicolumn{2}{|c|}{8 by 16 array } & \multicolumn{2}{|c|}{16 by 16 array } \\
\hline $\begin{array}{l}\text { Directivty }{ }_{M I N}, \mathrm{~dB} \\
\text { Pointng error, } \mathrm{dB} \\
\text { Polarization, } \mathrm{dB}\end{array}$ & \multicolumn{2}{|c|}{$\begin{array}{r}20.10 \\
0.14 \\
0.20 \\
\end{array}$} & \multicolumn{2}{|c|}{$\begin{array}{r}23.10 \\
0.14 \\
0.20 \\
\end{array}$} & \multicolumn{2}{|c|}{$\begin{array}{r}26.10 \\
0.14 \\
0.20 \\
\end{array}$} \\
\hline$L_{N A}, d B$ & NDISS L & $\begin{array}{r}\text { DISS L } \\
3.50\end{array}$ & NDISS L & $\begin{array}{r}\text { DISS L } \\
3.50\end{array}$ & NDISS L & $\begin{array}{r}\text { DISS L } \\
3.50 \\
\end{array}$ \\
\hline $\begin{array}{l}\text { Feed-thru, } d B \\
\text { Element, } d B \\
\text { Radome, } d B\end{array}$ & $\begin{array}{l}0.35 \\
0.35 \\
0.20\end{array}$ & $\begin{array}{l}0.10 \\
0.27 \\
0.30\end{array}$ & $\begin{array}{l}0.35 \\
0.35 \\
0.20\end{array}$ & $\begin{array}{l}0.10 \\
0.27 \\
0.30\end{array}$ & $\begin{array}{l}0.35 \\
0.35 \\
0.20\end{array}$ & $\begin{array}{l}0.10 \\
0.27 \\
0.30 \\
\end{array}$ \\
\hline $\begin{array}{l}\text { Sky temp, } k \\
\text { System temp, dBK } \\
G / T_{\text {PRED }} d B / K\end{array}$ & \multicolumn{2}{|c|}{$\begin{array}{r}5.00 \\
27.90 \\
-7.80\end{array}$} & \multicolumn{2}{|c|}{$\begin{array}{r}5.00 \\
27.90 \\
-4.80\end{array}$} & \multicolumn{2}{|c|}{$\begin{array}{r}5.00 \\
27.90 \\
-1.80\end{array}$} \\
\hline
\end{tabular}


Phase array performance prediction. The transmit loss budget and receive noise temperature computation used in EIRP and G/T calculations are shown in Tables 11 and 12 . The EIRP is computed by adding the total RF power to the directivity and subtracting the losses. The G/T is computed by subtracting the noise temperature (in dBK's) from the directivity. In both cases, the directivity is computed using Ball's array modeling software. The program computes the excitation function in the aperture and takes a Fast Fourier Transform (FFT) to generate the farfield Radiation Distribution Pattern (RDP). The peak and average powers are divided tc yield the array directivity. Factors such as aperture taper, phase shifter quantization errors, random phase errors, and element pattern are modeled. Figure 20 illustrates the transmit RDP's and Fig. 21 the receive RDP's at three main beam directions - boresight and maximum scan (60\% off boresight) in the two principle planes. The worst case scan planes are those which cut across the element rows. The effective spacing between elements ( 0.48 wavelengths) is greatest in these planes, and the grating lobe is quite close to real space. The best case scan planes are those which are parallel to the element rows. The effective spacing is 0.28 wavelengths, which keeps grating lobes far out of real space. In all of the cases shown, the patterns are well behaved and grating lobes do not appear.

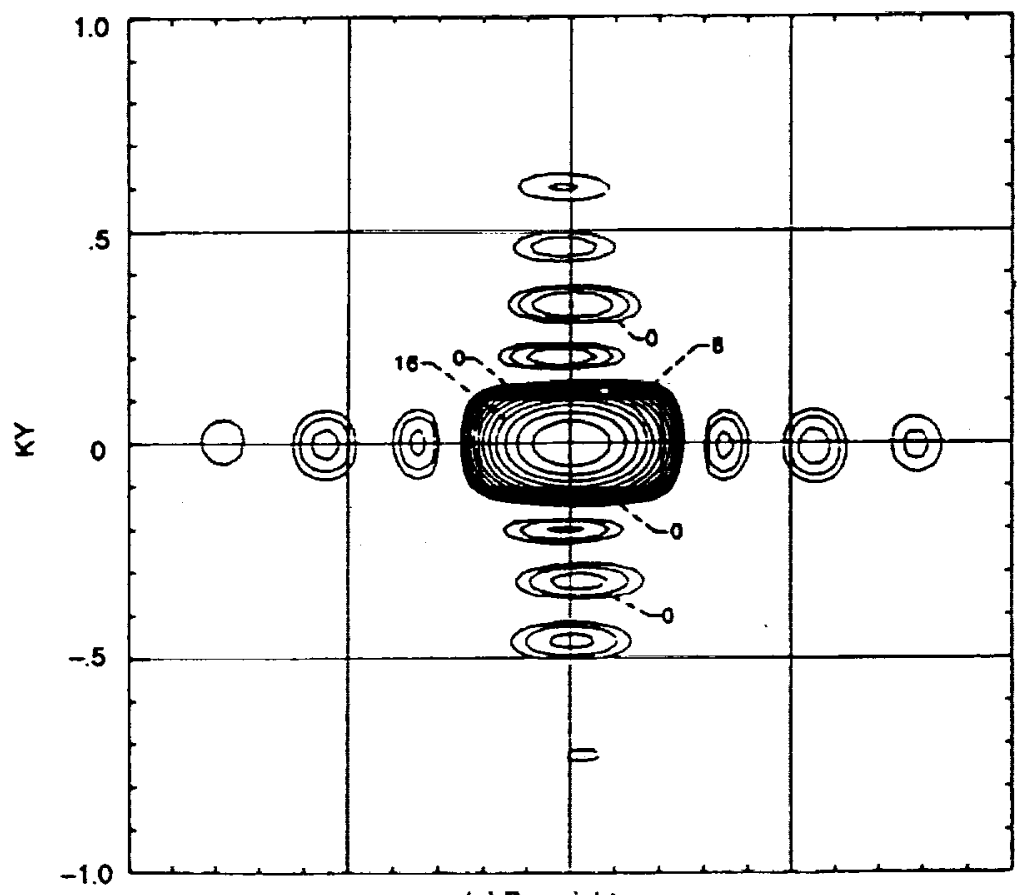

(a) Boresight scan.

Figure 20.-Transmit RDP for hybrid array. 


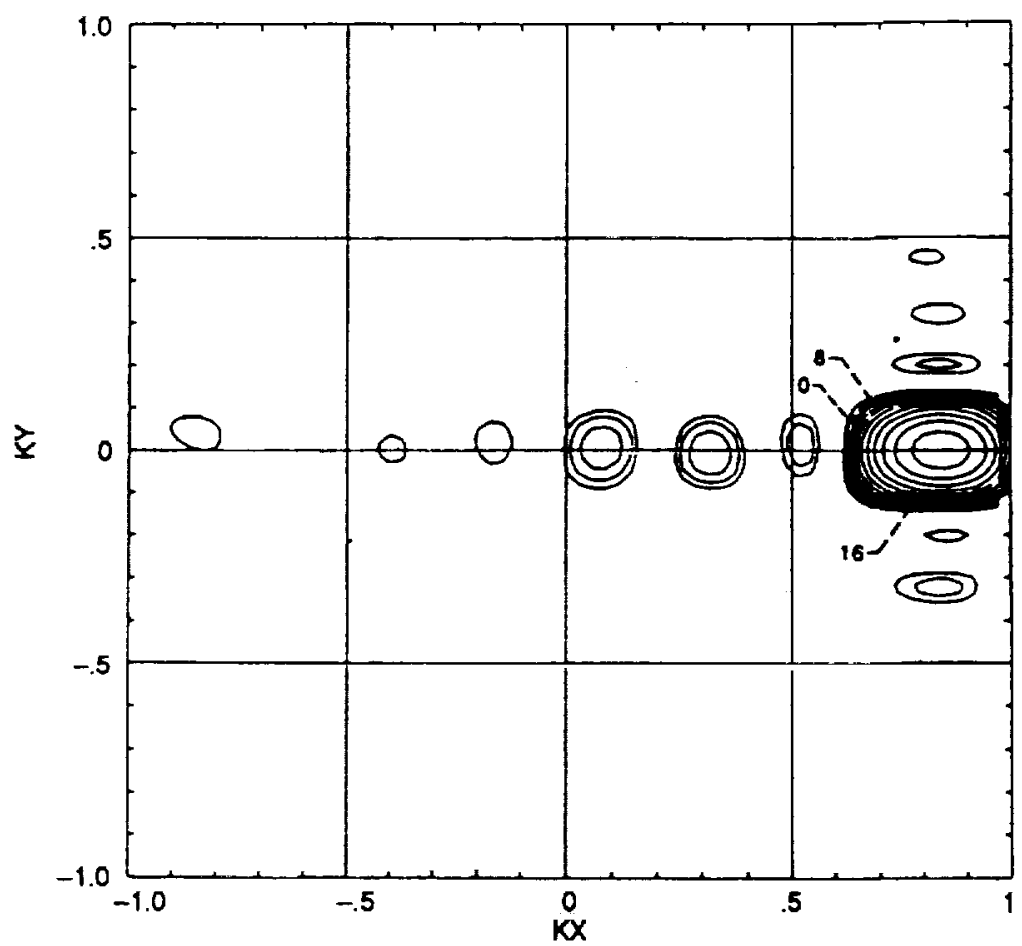

(b) Maximum scan in best case plan

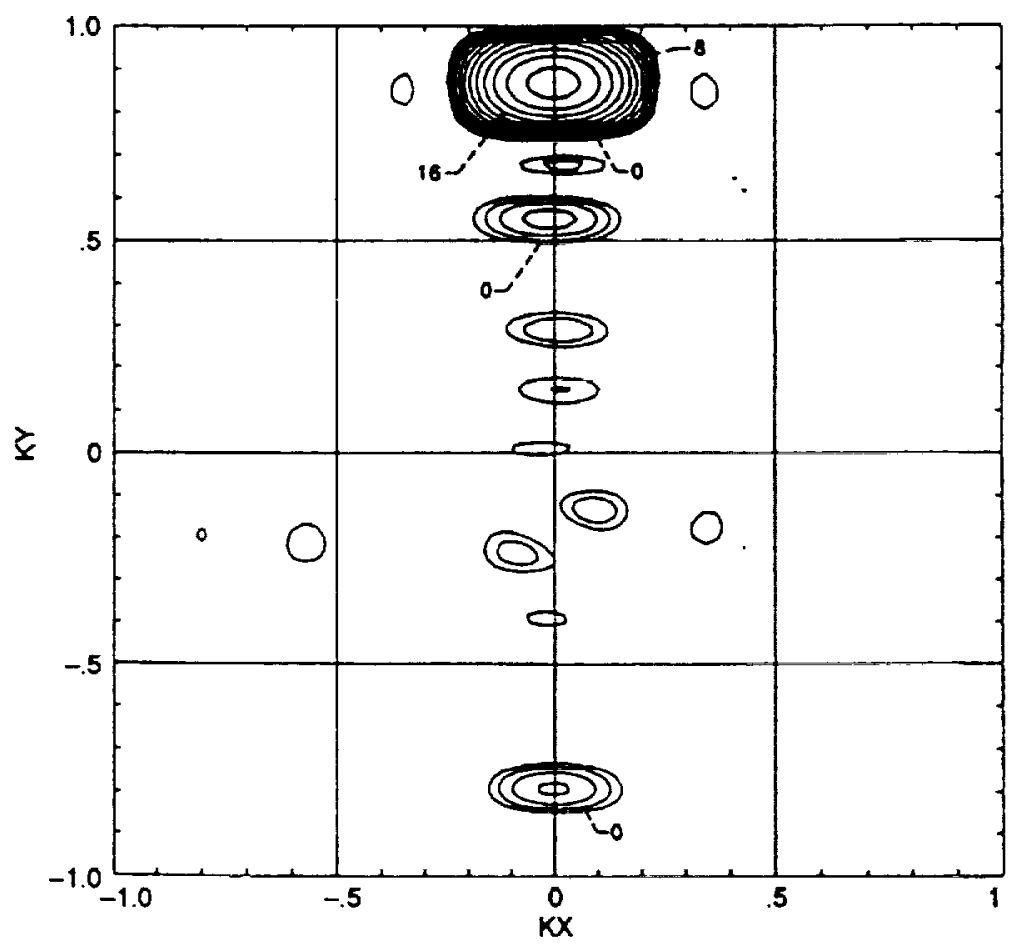

(c) Maximum scan in worst case plane.

Figure 20.-Concluded. 


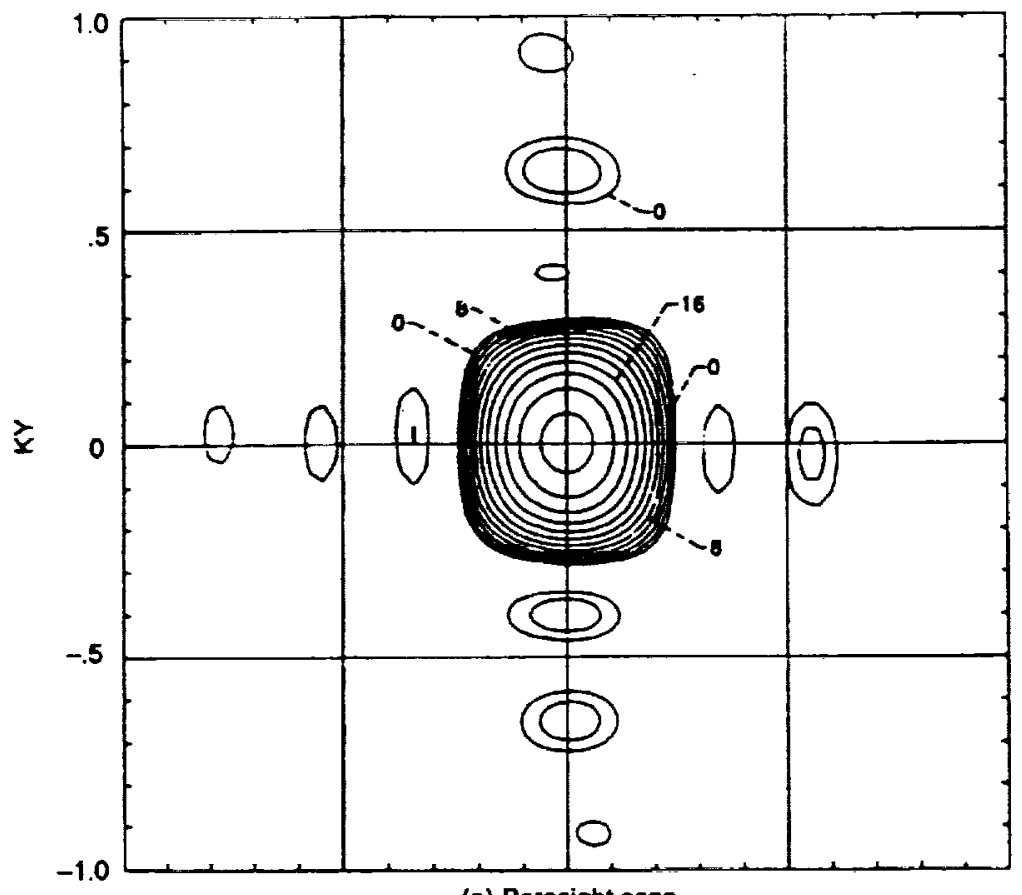

(a) Boresight scan

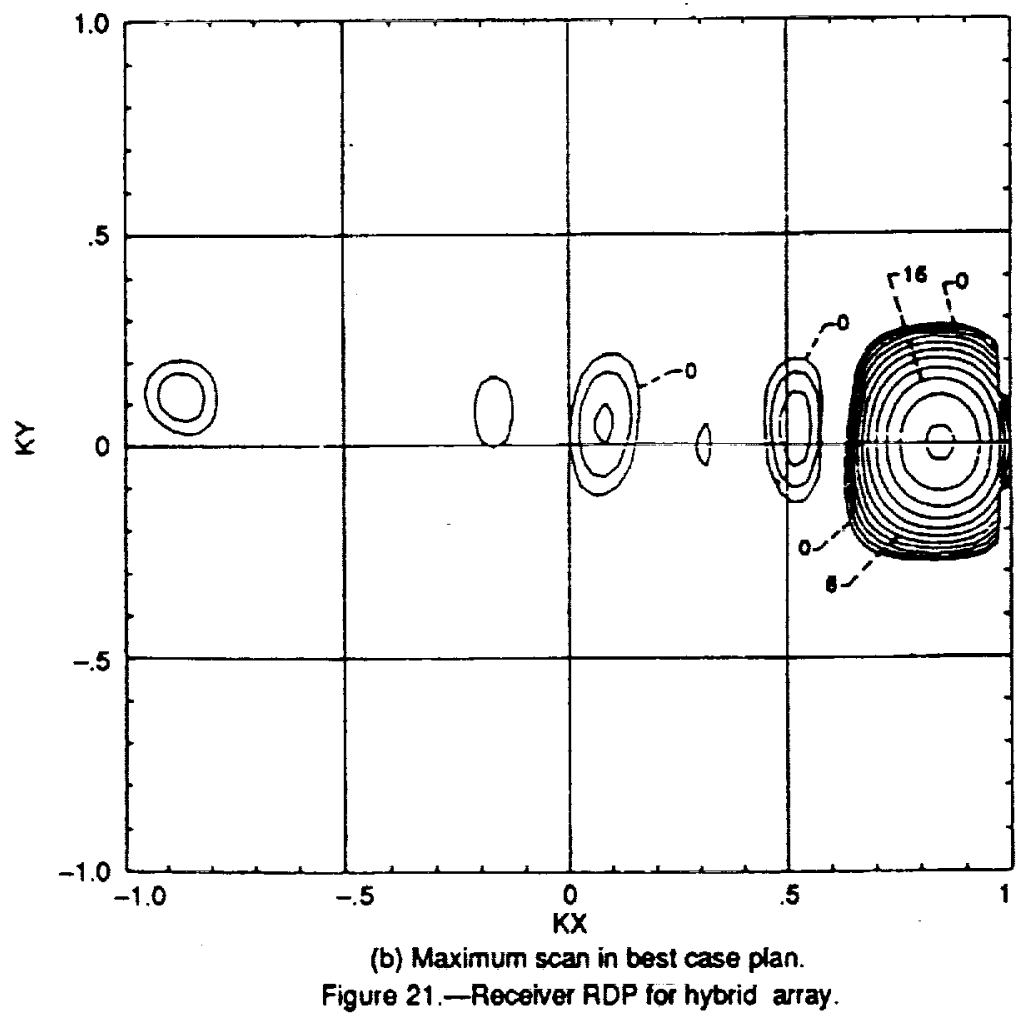




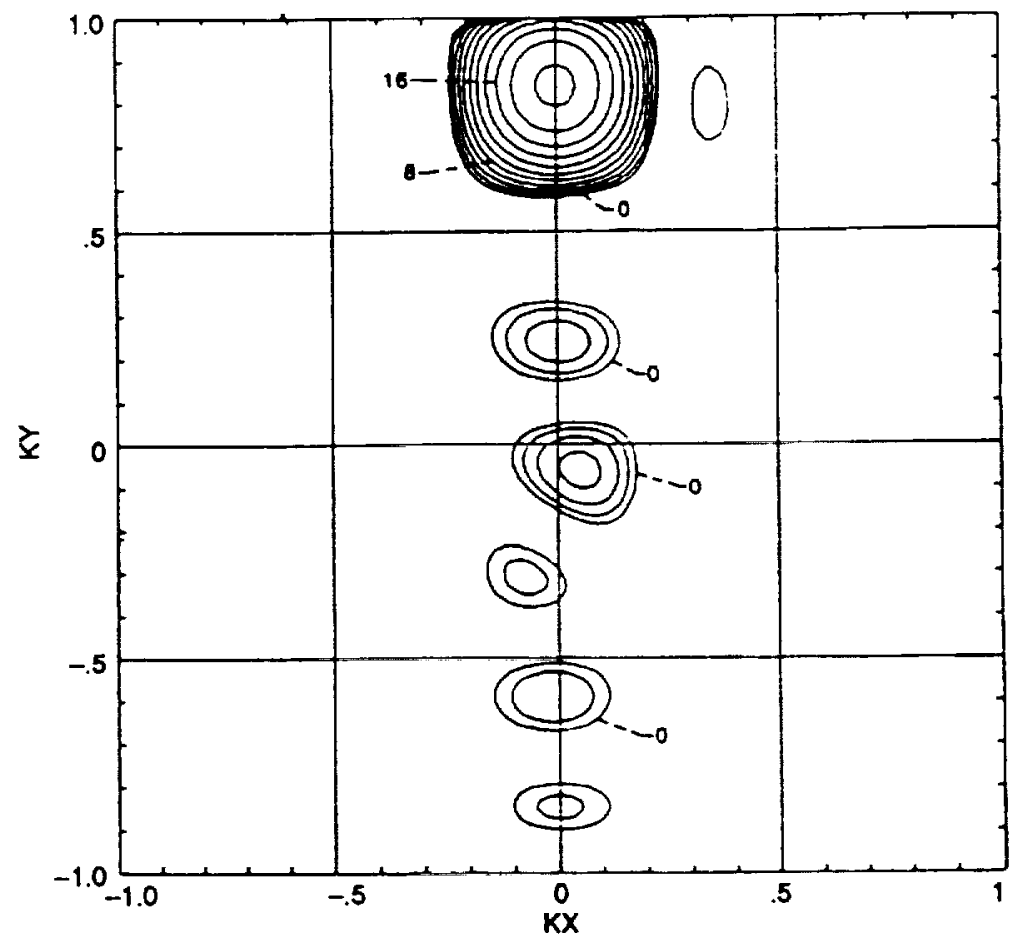

(c) Maximum scan in worst case plane.

Figure 21.-Concluded.

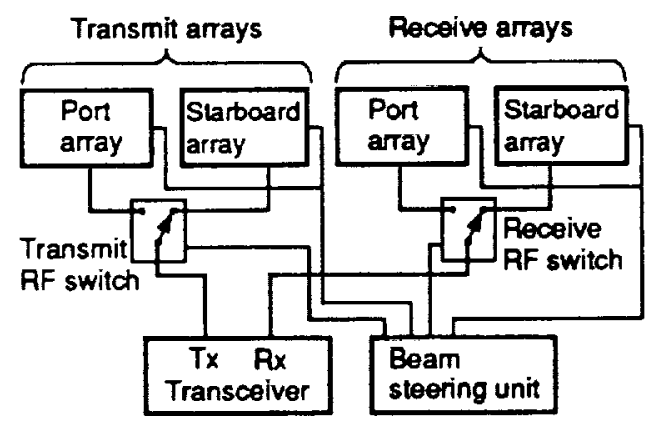

Fig. 22. Block diagram for system with wo transmit and receive amays.

Phase array installation. The block diagram for the two array. system is shown in Fig. 22. One transmit and one receive array are mounted on each side of the fuselage. The beam steering unit selects either the starboard or port side arrays, depending on which provides better coverage of the satellite, using two RF switches. In addition, the beam steering unit also sends the appropriate beam steering commands to the phase shifters.

It should be noted that this two antenna configuration cannot provide complete upper hemispherical coverage. There will always be two key holes (or blind spots) - one in front and another one in the aft of the aircraft. The size of these key holes is related to the array position, orientation, and maximum scan angle. Figure 23 quantifies the size of these key holes in terms of the percentage of required coverage space that can be spanned by the main beam. The first set of curves 

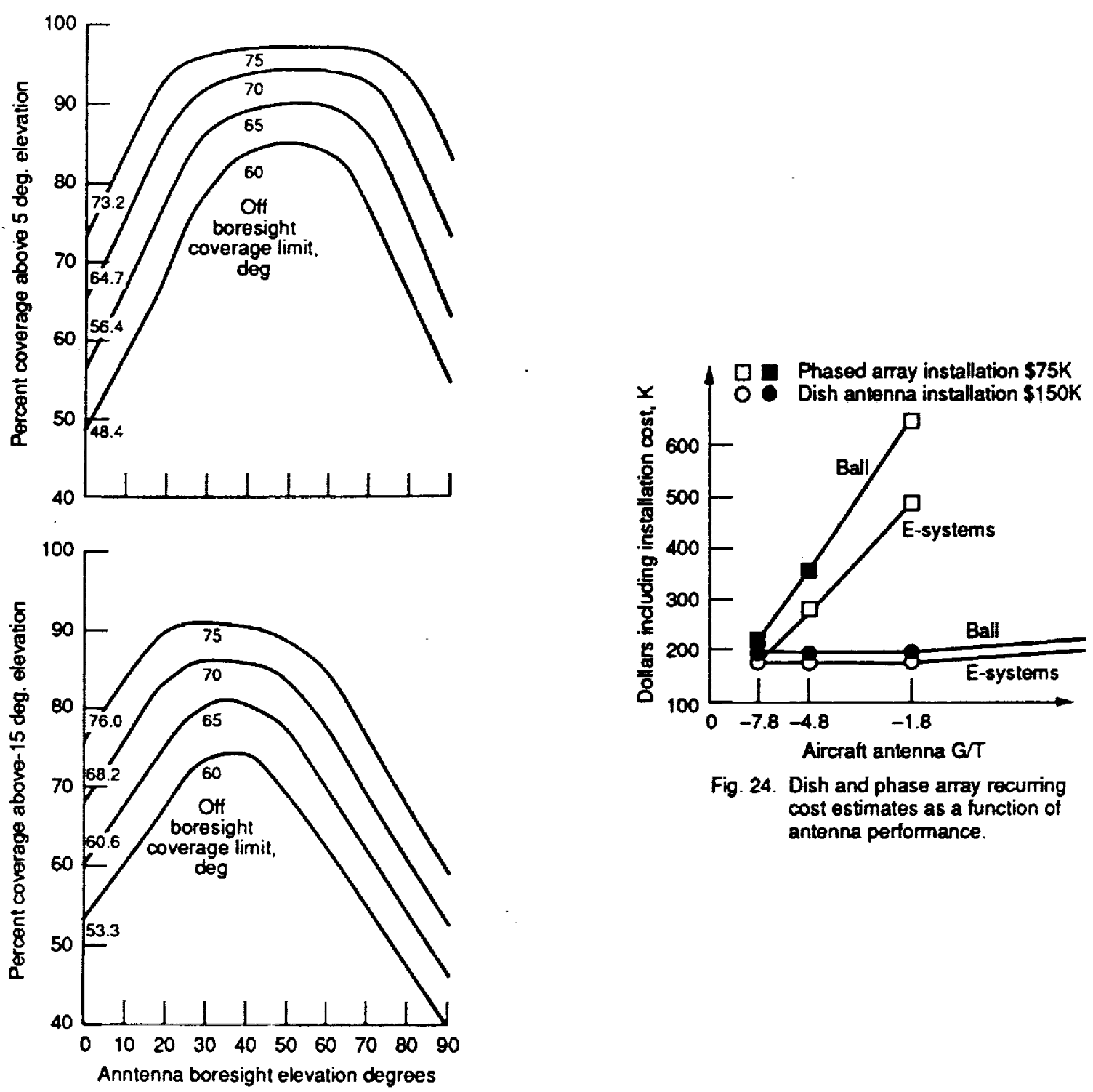

Fig. 24. Dish and phase array recurring cost estimates as a function of antenna performance.

Fig. 23. Two antenna coverage for $-15^{\circ}$ and $5^{\circ}$ coverage angle.

shows that the conformal antennas should be mounted with its boresight plot the percentage assuming that the required coverage space is from the aircraft zenith to $5^{\circ}$ above the aircraft's horizontal plane. It $t$ axis at about $45^{\circ}$ to $50^{\circ}$ from the aircraft's horizontal plane in order to maximize the percentage of coverage at about 85 percent. The second plot yields same kind of information assuming that the required coverage space is $-15^{\circ}$ and above with respect to the aircraft's horizontal plane.

Antenna Cost Estimates. Figure 24 summarizes the rough order of magnitude (ROM) cost estimates provided by the two antenna manufacturing companies (Jong, 1990) that conducted the studies. These are production model cost estimates derived for 1995 timeframe and under the assumption that an antenna manufacturing company would receive one time order for 1000 units. It shows that dish antenna cost remains constant over a wide range of performances while cost associated with phased array antenna varies directly with performance. The continuing technology 
evolution is expected to make phased array antenna very competitive cost-wise in the coming years.

\section{CONCLUSION}

A possible future operational system intended to provide Ka-band satellite communications services to the aviation community has been characterized. The salient features include higher communications capacity, significantly smaller antenna aperture for the aircraft terminals, and ample uncontested spectrum. The functional requirements and high level design concepts were discussed for the satellite, ground stations, the aircraft terminals, and system operation. The Ka-band aircraft antenna was studied in further detail to address its economical and technical issues. It is concluded that a future Ka-band satellite system for aeronautical communications is technically feasible and that aeronautical satellite communications services can be provided at an affordable rate if the future market is sufficiently large to justify a satellite with a peak capacity of 6000 full-duplex voice circuits.

\section{REFERENCES}

Agnew, C.E., et al.: The AMSC Mobile Satellite System. Proceedings of the Mobile Satellite Conference, W. Rafferty, ed., NASA CR-182964, 1988, pp.3-9.

GTE Airfone In-flight Telephone Service. The Sky's no longer the limit, System Overview Guide, 1989.

INMARSAT Aeronautical System Definition Model (SDM), Apr. 1989.

JPL Acts Mobile Terminal (AMT) Preliminary Design Review.

Feb. 7-8, 1991 .

Jong, H.: E-Systems, Inc. ECI Division, Analex Corporation Contract, Sept. 14, 1990.

Palmer, L.: ACTS Small Terminal Study. Hughes Network Systems, NASA/Analex Contract AC 90-695, Nov. 30, 1990.

Richards, R.: Deal boosts in-flight phone calls. USA Today, Sept. 13, 1990 .

Schmidt, F.: Skyphone Aircraft Antenna System Study. Ball Aerospace Systems Group, Analex Corporation Contract No. AC 90-691, Sept. 30. 1990.

Stamp, R.G.: Satellites and North Atlantic air traffic management: the bottom line. Operational Research and Analysis, Civil Aviation Authority, UK; Proceedings of the international conference on mobile satellite communications, London, July, 1989. 
Wood, P.; and Smith, K.: World-wide Aeronautical Satellite Communications. Proceedings of the Mobile Satellite Conference, W. Rafferty, ed., NASA CR-182964, 1988, pp. 57-62. 


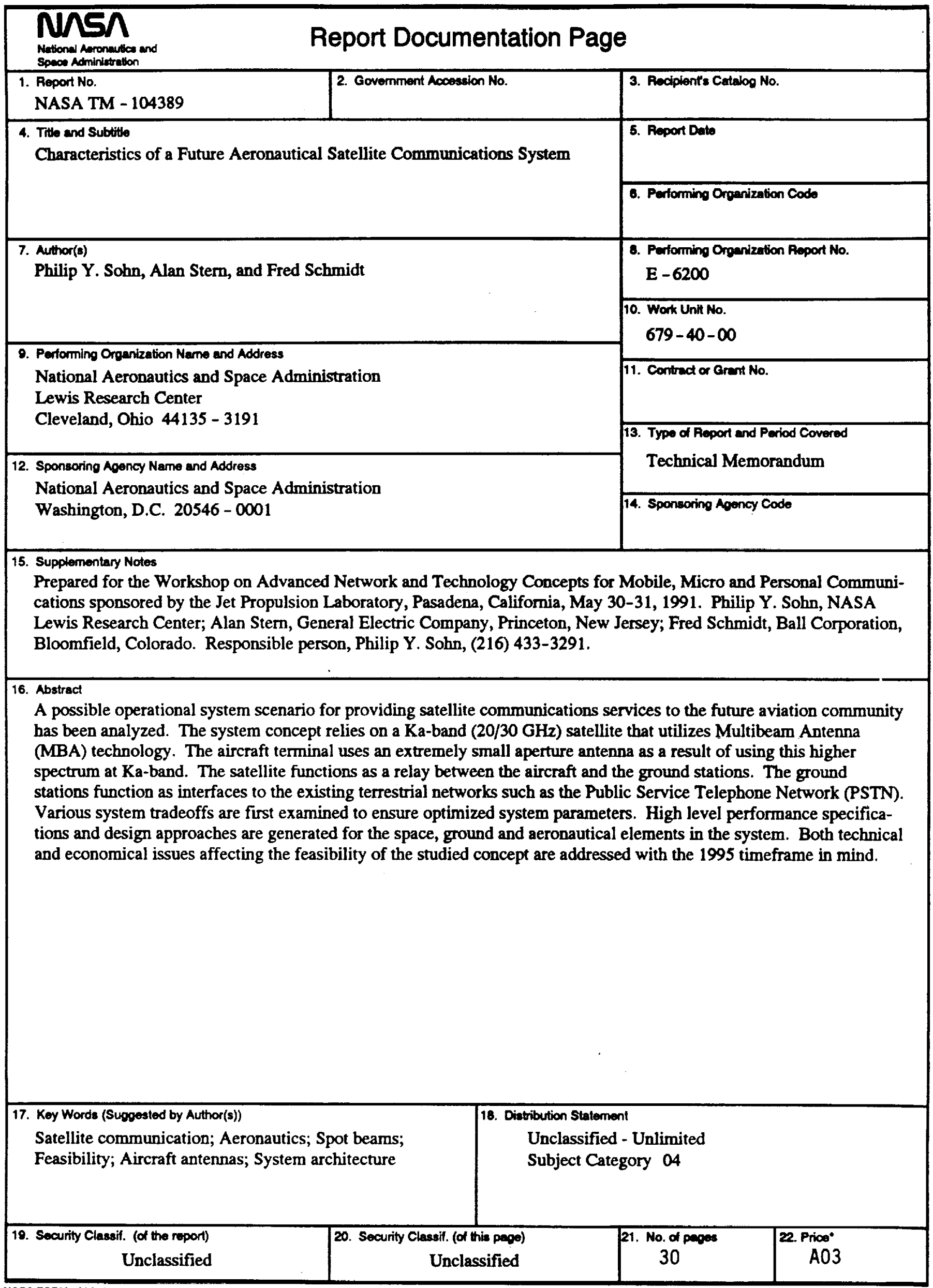




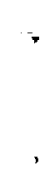

